\title{
Regionalized Linear Models for River Depth Retrieval Using 3-Band Multispectral Imagery and Green LIDAR Data
}

\author{
Håkon Sundt ${ }^{1, *}$, Knut Alfredsen ${ }^{1}$ (D) and Atle Harby ${ }^{2}$ \\ 1 Department of Civil and Environmental Engineering, Norwegian University of Science and Technology, \\ 7491 Trondheim, Norway; knut.alfredsen@ntnu.no \\ 2 SINTEF Energy Research, 7465 Trondheim, Norway; atle.harby@sintef.no \\ * Correspondence: haakon.sundt@gmail.com
}

Citation: Sundt, H.; Alfredsen, K.; Harby, A. Regionalized Linear Models for River Depth Retrieval Using 3-Band Multispectral Imagery and Green LIDAR Data. Remote Sens. 2021, 13, 3897. https://doi.org/ $10.3390 /$ rs13193897

Academic Editor: Dimitrios D. Alexakis

Received: 17 August 2021 Accepted: 24 September 2021 Published: 29 September 2021

Publisher's Note: MDPI stays neutral with regard to jurisdictional claims in published maps and institutional affiliations.

Copyright: (c) 2021 by the authors. Licensee MDPI, Basel, Switzerland. This article is an open access article distributed under the terms and conditions of the Creative Commons Attribution (CC BY) license (https:/ / creativecommons.org/licenses/by/ $4.0 /)$.

\begin{abstract}
Bathymetry is of vital importance in river studies but obtaining full-scale riverbed maps often requires considerable resources. Remote sensing imagery can be used for efficient depth mapping in both space and time. Multispectral image depth retrieval requires imagery with a certain level of quality and local in-situ depth observations for the calculation and verification of models. To assess the potential of providing extensive depth maps in rivers lacking local bathymetry, we tested the application of three platform-specific, regionalized linear models for depth retrieval across four Norwegian rivers. We used imagery from satellite platforms Worldview-2 and Sentinel-2, along with local aerial images to calculate the intercept and slope vectors. Bathymetric input was provided using green Light Detection and Ranging (LIDAR) data augmented by sonar measurements. By averaging platform-specific intercept and slope values, we calculated regionalized linear models and tested model performance in each of the four rivers. While the performance of the basic regional models was comparable to local river-specific models, regional models were improved by including the estimated average depth and a brightness variable. Our results show that regionalized linear models for depth retrieval can potentially be applied for extensive spatial and temporal mapping of bathymetry in water bodies where local in-situ depth measurements are lacking.
\end{abstract}

Keywords: remote sensing; bathymetry; satellite imagery; LIDAR; river management

\section{Introduction}

Rivers provide a range of landscape functions and ecosystem services [1]. While rivers have been supplying means of recreation, transportation, and electricity production, the utilization of rivers has come at a certain cost, introducing physical, ecological, and hydrological alterations. Proposing relevant mitigation measures requires the appropriate analytical tools. This includes a solid bathymetric basis on which to build the assessment strategy and the use of hydraulic, hydrological, sediment, physio-chemical, and ecological models.

While remote sensing (RS) technologies have been available for many years [2,3], recent developments suggest an increased interest in the analytical possibilities of RS [4,5]. RS has been applied for many different purposes in river studies and is rapidly becoming more available for analytical use [6-9]. Examples of use include automated grain size mapping [10], fluvial patterns and sediment surface topography [11,12], and habitat mapping for salmonids $[13,14]$.

The basis for many river assessments is riverbed topography coupled with hydraulic models [15,16]. Hydraulic models often depend on an adequately defined bathymetry $[17,18]$ and have historically been applied in relatively short river sections rather than large river reaches due to lack of resources for extensive bathymetric mapping. There are many methods to retrieve riverbed data ranging from manual methods using hand-held sticks and instruments by wading or from boats to more semi-automated methods like sonars, acoustic doppler current profilers (ADCP), Light Detection and Ranging (LIDAR), and optical instruments, 
mostly carried by remotely operated vehicles (ROV), boats, drones, helicopters, airplanes, and satellites. Some of these methods still require intensive manual effort to collect data for large river reaches, and they are not further discussed here.

Airborne devices such as LIDARs may provide users with extensive, high-resolution bathymetric models [19], but the collection and processing of LIDAR data can potentially be costly and time-consuming $[20,21]$. While the application of RS imagery may result in lower-resolution models when compared to LIDAR-derived data, it can still be a sensible alternative for the mapping of river bathymetry [22,23]. Often, RS imagery is collected repeatedly in both space and time, adding spatial and temporal elements that can be utilized in river assessments [24]. The main sources of RS imagery are satellites and aircraftbased instruments [25]. While access to local aerial images may be restricted, satellite imagery is often readily available at low- or no-costs from a range of global archives.

Lyzenga [26] introduced the use of RS image band combinations for water depth extraction. Building on the Lyzenga image band combination concept, Legleiter et al. [27] introduced OBRA (Optimal Band Ratio Analysis) for the identification of optimal band combinations. Further development of the concept was done by Legleiter \& Harrison [28] by assessing different types of equations for the relation between image-derived quantities and depth. Additional methods include MODPA (Multiple Optimal Depth Predictors Analysis), where multiple predictors are included to enhance water depth extraction, and SMART-SDB (Sample-specific multiple band ratio technique for satellite-derived bathymetry), where local adjustments to band ratio models are applied [29,30].

In addition to being dependent on the platform-specific sensor technology, the relational quality between image-derived quantity and water depth also depends on factors like ground pixel resolution, substrate color, water column characteristics, and water depth itself [31]. While "clear" rivers are (seasonally) present in Norway, many rivers are semior non-transparent due to suspended sediments, organic matter, and the presence of periphyton reducing water column transparency and obscuring riverbed visibility, especially in the deeper parts of the river.

While a small but increasing number of Norwegian rivers have been mapped using green LIDAR, most rivers lack extensive bathymetric coverage. Occasional mapping of rivers done many years ago may also not be used anymore, as the riverbed topography may have changed due to sedimentation and erosion caused by flood events, ice scouring, or other factors. This may emphasize the need for updating outdated bathymetric maps while also providing access to bathymetry in previously unmapped rivers.

Increasing the availability of bathymetric maps on a regional or national scale could provide a better foundation for river management. Norwegian river managers are currently facing multiple challenges. The European Water Framework Directive (WFD) requires the characterization and classification of all water bodies. So far, the methods and tools to do this in a cost-effective way are missing. About $2 / 3$ of the large rivers in Norway are regulated for hydropower. Many of these will undergo a revision of terms in the coming years, as they reach 30 years of operation [32]. Both the implementation of the WFD and the revision of terms in hydropower regulated rivers would most likely require mitigation measures to be carried out. These measures could be the release of environmental flows, habitat improvements, and alterations of geomorphology. In addition, the increased frequency and magnitude of intensive precipitation events due to climate change increase the risk of damaging flood events in Norwegian rivers [33]. All these factors require improved knowledge and data from rivers, highlighting the need for adequate and spatial extensive river bathymetry data.

As satellite imagery often covers large parts of catchments, both spatially and temporally, estimating depth from image data can be an essential tool for setting up a range of river applications to meet these new challenges for river management. In addition to the challenges mentioned above, extensive river bathymetry data are also important for planning urban, industrial, and infrastructure development close to or across the riverscape. 
While a range of models for local depth retrieval has been tested and applied, there is a lack of studies analyzing the potential transferability and application of platform-specific models across rivers. The main goal of our study was to test the use of regionalized linear models for depth retrieval in a Norwegian setting to provide a potential method for extensive depth mapping in water bodies where local bathymetry is lacking. The regionalized linear models were set up by calculating and averaging the platform-specific depth to band ratio intercept and slope coefficients across four rivers located within the same geographical region. Using local LIDAR and sonar bathymetry as depth input, we set up linear models for three RS platforms: (1) high-resolution Worldview-2 satellite imagery, (2) low-resolution Sentinel-2 satellite imagery, and (3) local high-resolution aerial imagery. Our research objectives were:

(1) To test and assess depth retrieval using linear models for three different platforms across four Norwegian rivers with slightly different characteristics.

(2) To develop and test the application and transferability of platform-specific, regionalized models for depth retrieval across the four study sites.

\section{Materials and Methods}

Four non-connected rivers located in Central Norway were used in the study: Gaula, Gudbrandsdalslågen (hereafter Lågen), Nea, and Surna (Figure 1 and Table 1). River Gaula is dominated by a sand and gravel substrate and runs through a relatively wide U-shaped valley. While floods still affect the hydromorphology, embankments and historical gravel outtakes have altered the geomorphology and reduced the dynamic movement of the riverbed in parts of Gaula. River Lågen is dominated by silt/sand and gravel substrate and runs through a wide valley bottom. River Nea is dominated by gravel and occasional rocks and runs through a V-shaped valley in the upstream part and a u-shaped valley in the lower part. River Surna is a gravel-bed-dominated river that runs through a Ushaped valley. Rivers Nea and Surna are regulated by hydropower with an upstream dam and reservoir, a bypass section, and an outlet in the lower part, while river Lågen is regulated by a run-of-the-river hydropower plant. River Gaula is not directly affected by hydropower regulation.
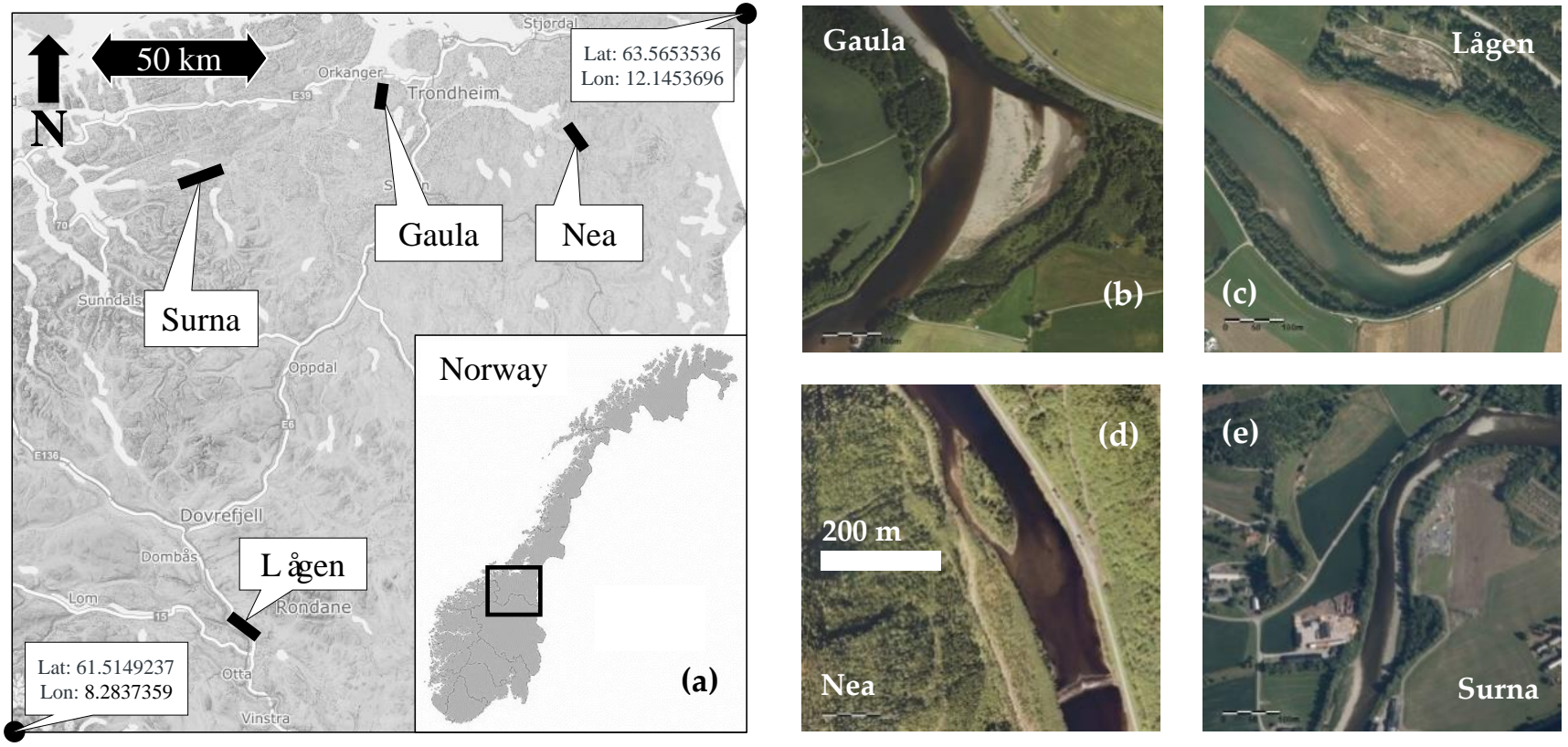

Figure 1. Overview of the study areas: (a) regional locations of the four rivers in central Norway; (b-e) aerial images of the river sections used as training data for cross-sectional image pixel and in-situ depth extraction. The scale for all river sections is given in (d). Aerial images by (C) Kartverket and Geovekst. 
Table 1. River drainage area and training data river section mean annual flow, width, section length, and channel aspect ratio, A. Channel aspect ratio is calculated as average width by depth in one of the Worldview-2 images in the four river sections.

\begin{tabular}{ccccc}
\hline River & $\begin{array}{c}\text { Drainage Area } \\
\left(\mathbf{k m}^{\mathbf{2}}\right)\end{array}$ & $\begin{array}{c}\text { Mean Annual } \\
\left.\text { Flow } \mathbf{( m}^{\mathbf{3}} \mathbf{s}^{-\mathbf{1}}\right)\end{array}$ & $\begin{array}{c}\text { Average Width } \\
\mathbf{( m ) / S e c t i o n} \\
\text { Length } \mathbf{( m )}\end{array}$ & $\begin{array}{c}\text { Channel Aspect } \\
\text { Ratio, A }\end{array}$ \\
\hline Gaula & 3660 & 96.6 & $85.3 / 293.5$ & 90.7 \\
Lågen $^{1}$ & 1828 & 32.7 & $72.9 / 443.6$ & 58.3 \\
Nea $^{2}$ & 1519 & 1.5 & $95.9 / 322.4$ & 223.0 \\
Surna $^{3}$ & 1199 & 8.2 & $39.1 / 230.9$ & 56.6 \\
\hline
\end{tabular}

${ }^{1}$ Regulated by hydropower. ${ }^{2}$ Regulated by hydropower. $1.5 \mathrm{~m}^{3} \mathrm{~s}^{-1}$ is the minimum flow release from May through September. Local runoff applies in addition. ${ }^{3}$ Regulated by hydropower. Mean flow in bypass reach/downstream powerplant outlet.

\subsection{Data}

\subsubsection{Riverbed Topography}

We accessed a national public database for red and green LIDAR data, available at www.hoydedata.no, acessed on 17 August 2021 [34]. Using polygons to define the area of interest (AOI) in each of the four rivers, we included the specific river reaches in each of the study areas in addition to a buffer zone of approximately $10 \mathrm{~m}$ of dry terrain on each bank. For each AOI, we downloaded a $1 \times 1 \mathrm{~m}$ orthorectified digital terrain model (DTM) based on a nationwide red LIDAR mapping project. As all standard DTMs in the database were based on a non-water penetrating red LIDAR point cloud, the wet parts of rivers were given as a water surface, per classification from the point cloud. In the same database, a selection of sections of rivers have bathymetry available based on green LIDAR point clouds, and some of these point clouds also include supplementary local measurements of bathymetry using multibeam sonar to complement missing data in deeper river sections. For rivers Gaula and Lågen, we downloaded bathymetry point clouds for the respective AOIs. For each of the two rivers, we used the point clouds to create riverbed topography raster files using natural neighbor interpolation. In river Nea, we sampled riverbed topography using boat mounted SonTek M9 ADCP. Approximately 12,000 points were collected on a $3 \mathrm{~km}$ river stretch. We then used the points for natural neighbor interpolation to create a riverbed topography raster file. For river Surna, we were given access to a green LIDAR bathymetric dataset collected by the hydropower operator Statkraft [35], covering the study reach. A summary of parameters for the underlying point clouds and terrain datasets is given in Table 2.

Table 2. Equipment used for the acquisition of point clouds used to calculate the river-specific terrain datasets.

\begin{tabular}{|c|c|c|c|c|c|}
\hline River & Platform & Operator & Date of Acquisition & $\begin{array}{c}\text { Point } \\
\text { Density }\end{array}$ & $\begin{array}{c}\text { Accuracy } \\
(\mathrm{dz})(\mathrm{m})\end{array}$ \\
\hline Gaula & $\begin{array}{l}\text { Optech Titan } \\
\text { snr } 349\end{array}$ & TerraTec & $\begin{array}{c}\text { 26 September } \\
\text { 2016-11 October } 2016\end{array}$ & $4 \mathrm{pt} / \mathrm{m}^{2}$ & 0.002 \\
\hline Lågen & $\begin{array}{c}\text { Optech Titan } \\
\text { snr } 349 \\
\text { SonTek }\end{array}$ & TerraTec & $\begin{array}{l}20 \text { September } 2015- \\
21 \text { September } 2015\end{array}$ & $4 \mathrm{pt} / \mathrm{m}^{2}$ & 0.024 \\
\hline Nea & $\begin{array}{l}\text { RiverSurveyor } \\
\text { M9 [36] }\end{array}$ & NTNU & 25 October 2019 & $0.06 \mathrm{pt} / \mathrm{m}^{2}$ & - \\
\hline Surna & RIEGL VQ-880 G & AHM & $\begin{array}{c}20 \text { August } \\
\text { 2016-26 August } 2016\end{array}$ & $>1 \mathrm{pt} / \mathrm{m}^{2}$ & - \\
\hline
\end{tabular}

The bathymetric raster in each river was resampled and snapped to match the resolution and borders of the cells (i.e., pixels) in the individual satellite and aerial imagery. Thereby, each set of imagery had its georeferenced bathymetric map. To establish the georeferenced water surface elevation along the river sections, we used local satellite imagery in combination with the red LIDAR raster to set up polygons with the same 
water surface elevation. To obtain water surface maps, we used the Normalized Difference Vegetation Index (NDVI) method on the satellite imagery, using a combination of the red and near-infrared (NIR) bands [37]. In the resulting raster, negative values indicated water surface, and positive values indicated dry land. We reclassified the raster by letting a value of 1 indicate water, and a value of 0 indicate dry land, and, finally, created a polygon representing the water surface classification outline. Using the red LIDAR raster as input, we extracted the water surface elevation using the classification polygon file. In addition, we set up a new water surface polygon file based on areas with the same elevation to inspect and extract local water surface slope. Based on the extracted water surface elevations, we created depth raster files by subtracting the bathymetric raster from the local water surface elevation. Further adjustment of local water surface elevations due to different flows during image acquisition was done during the subsequent analysis.

\subsubsection{Platform Imagery}

Three sources of imagery were used for analysis: (1) four-band red, green, blue, and near-infrared high-resolution Worldview-2 satellite images; (2) four-band red, green, blue, and near-infrared Sentinel-2 satellite images; and (3) three-band high-resolution aerial images (Table 3). Worldview-2 images (๑ TPMO (2020)) were provided by the European Space Agency [38]. We did a manual conversion to obtain top-of-atmosphere (ToA) reflectance pixel values. ToA reflectance Sentinel-2 images were downloaded via the Copernicus Open Access Hub [39], while aerial images were acquired through the Norwegian mapping authority aerial image repository at www.norgeibilder.no, acessed on 17 August 2021. The aerial images were analyzed using raw digital numbers (DN) without any atmospheric correction.

Table 3. Platform image information summary.

\begin{tabular}{|c|c|c|c|c|c|}
\hline River & Image Source & Image No. & $\begin{array}{l}\text { Resolution } \\
\text { (m) }\end{array}$ & Acquisition Date & Discharge \\
\hline \multirow[t]{5}{*}{ Gaula } & Worldview-2 & 1 & 2.04 & 9 May 2017 & - \\
\hline & & 2 & 2.07 & 27 August 2019 & $50^{1}$ \\
\hline & Sentinel-2 & 1 & 10 & 19 August 2016 & $50^{1}$ \\
\hline & & 2 & 10 & 26 April 2019 & - \\
\hline & Aerial image & 1 & 0.5 & 6 June 2016 & $75^{1}$ \\
\hline \multirow[t]{6}{*}{ Lågen } & Worldview-2 & 1 & 2.05 & 7 September 2019 & 63 \\
\hline & & 2 & 2.05 & 8 September 2019 & 58 \\
\hline & Sentinel-2 & 1 & 10 & 30 June 2018 & 35 \\
\hline & & 2 & 10 & 3 July 2018 & 28 \\
\hline & & 3 & 10 & 4 August 2019 & 49 \\
\hline & Aerial image & 1 & 0.5 & 9 September 2015 & 42 \\
\hline \multirow[t]{7}{*}{ Nea } & Worldview-2 & 1 & 1.65 & 17 May 2018 & $20^{1}$ \\
\hline & & 2 & 2.06 & 16 May 2019 & $30^{1}$ \\
\hline & Sentinel-2 & 1 & 10 & 28 July 2019 & $10^{1}$ \\
\hline & & 2 & 10 & 4 August 2019 & $10^{1}$ \\
\hline & & 3 & 10 & 26 September 2019 & $10^{1}$ \\
\hline & Aerial image & 1 & 0.2 & 2 June 2017 & $40^{1}$ \\
\hline & & 2 & 0.2 & 27 July 2018 & $5^{1}$ \\
\hline \multirow[t]{6}{*}{ Surna } & Worldview-2 & 1 & 2.02 & 5 August 2019 & $14^{1}$ \\
\hline & & 2 & 2.05 & 20 October 2019 & $12^{1}$ \\
\hline & Sentinel-2 & 1 & 10 & 26 April 2019 & $96^{1}$ \\
\hline & & 2 & 10 & 28 July 2019 & $8^{1}$ \\
\hline & & 3 & 10 & 26 September 2019 & $4^{1}$ \\
\hline & Aerial image & 1 & 0.1 & 30 June 2018 & $6^{1}$ \\
\hline
\end{tabular}

${ }^{1}$ Discharge is estimated based on expert knowledge. 
All satellite images were orthorectified using the red-LIDAR-based terrain raster datasets. In addition, minor adjustments were done by shifting images in the $x$-y-plane to match the local high-resolution aerial images, used as georeferencing baseline. No smoothing was done on any of the images.

\subsection{Data Analysis}

\subsubsection{Selecting Band Combinations}

After a preliminary evaluation of both linear and polynomial methods, we decided to base the work on Legleiter et al. [28] and analyzed the linear relationship between depth and image pixel values as given in Equation (1).

$$
d=b_{0}+b_{1} X
$$

where $d$ is depth, $X$ is an image pixel-derived quantity, and $b_{0}$ and $b_{1}$ are the intercept and slope of the linear relationship. $b_{0}$ and $b_{1}$ form the coefficient vector $b=\left[b_{0} b_{1}\right]$. X from Equation (1) was defined as two different band combinations in our study:

$$
\begin{aligned}
& X_{g}=\ln \left(p_{g} / p_{r}\right) \\
& X_{b}=\ln \left(p_{b} / p_{r}\right)
\end{aligned}
$$

where $p$ is the respective band image pixel value (with subscripts $b, g$, and $r$ representing blue, green, or red bands, respectively). For the Worldview-2 and Sentinel-2 images, $p$ represented top-of-atmosphere reflectance values, while for the local aerial images, $p$ represented raw digital number values (DN). Band combinations were selected based on previous studies by Legleiter et al. [23] and Shintani and Fonstad [40], where analysis indicated that bands with the highest spectral values (i.e., red available in our case) as the denominator in many cases provided the best results. The blue and green bands were both subsequently chosen as the numerators. A pre-study assessment in our rivers confirmed the choice of band combinations.

\subsubsection{The Study Framework}

The data analysis was done using two sets of data: (1) cross-sectional training data and (2) polygon validation data (as given by the corresponding numbers in Figure 2). The training data was used for setting up local and regional linear models for depth retrieval for each platform (Worldview-2, Sentinel-2, and aerial images). The validation data was used for assessing the quality of the linear models when applied in each of the four rivers. The separate steps of data analysis apply to each of the four rivers and are summarized in short below (as given by the corresponding lettering in Figure 2) and described in full in the following chapters.

[A] We sampled image pixel quantities for the bands red, green, and blue along with insitu depth in 17 cross-sections for platforms Worldview-2, Sentinel-2, and aerial images.

[B] Using linear regression, we calculated coefficients $b_{0, \text { dir }}$ and $b_{1, \text { dir }}$ for the relationship between $X_{g}, X_{b}$, and depth, as given in Equations (1)-(3).

[C] By assessing the coefficient of determination $\left(R^{2}\right)$ for each cross-section, we removed all cross-sections with an $\mathrm{R}^{2}$ less than 0.60 to obtain coefficients $b_{0, \text { corr }}$ and $b_{1, \text { corr }}$

[D] Based on the remaining cross-section, we averaged coefficients $b_{0, \text { corr }}$ and $b_{1, \text { corr }}$ for each platform across the four rivers to obtain a regional set of coefficients $b_{0, \text { reg }}$ and $b_{1, \text { reg. }}$.

[E] We assessed and tested the relationship between the model coefficients $b_{0, d i r}$ and $b_{1, d i r}$ and variables average depth and image brightness.

[F] Using the relationships from [E], we calculated a corrected set of regional coefficients $b_{0, r e g_{-} d b r}$ and $b_{1, \text { reg_d }} d b r$ for each river.

[G] In a separate validation polygon in each of the four rivers, we applied the models from $[B],[D]$, and $[F]$ to test and assess the model quality. 


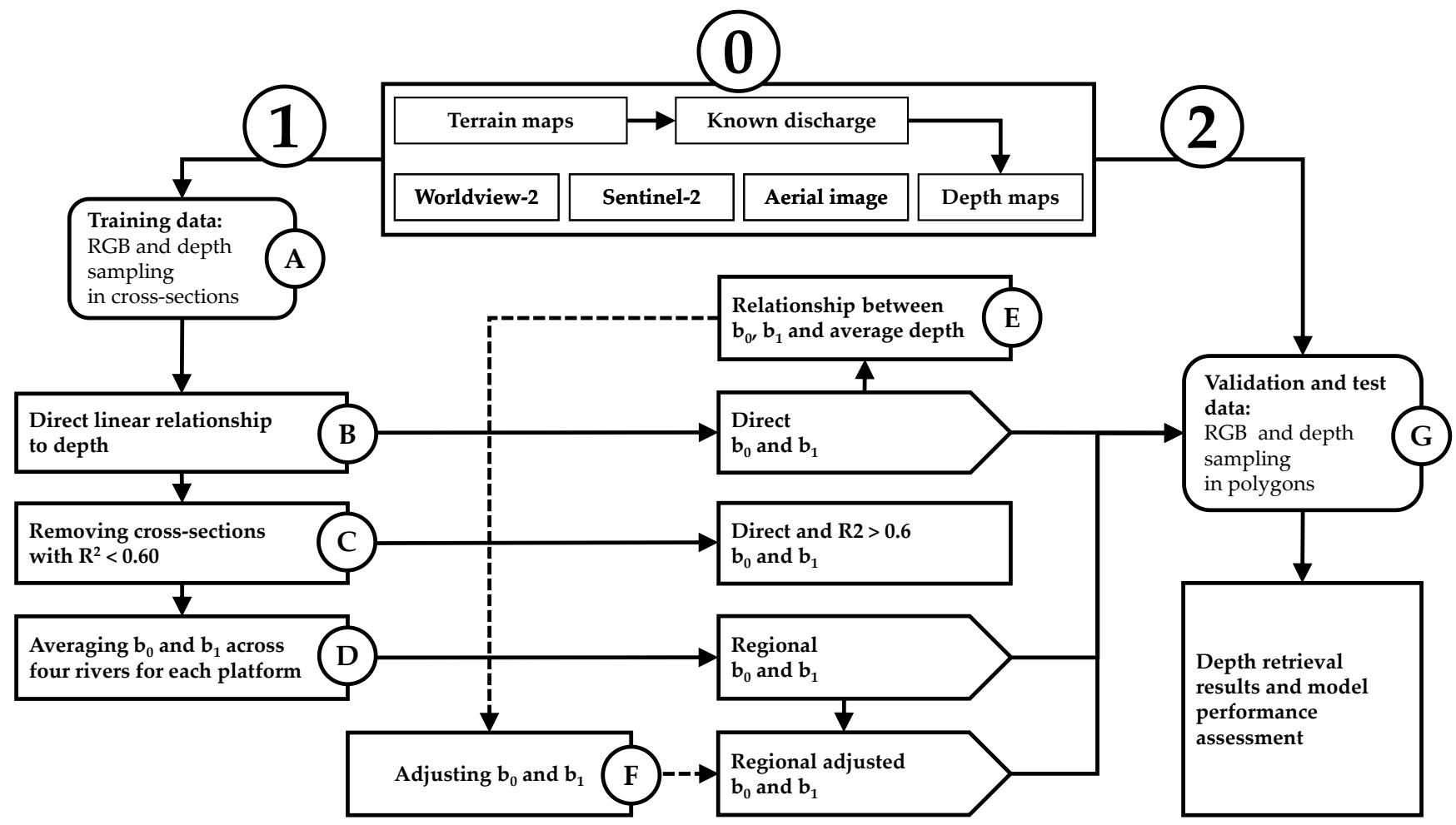

Figure 2. The study framework. Starting with the top box (0) displaying the study input data, the data analysis takes two pathways: (1) using RGB pixel values in river cross-sections to set up the different relationships between depth and image pixel quantities in steps A through F, and (2) testing and validating former relationships in a validation polygon in step G.

\subsubsection{Cross-Sectional Training Data Sampling}

A single river section (in the range of 232-443 m) was selected as training data input in each of the four rivers. Sections were specifically chosen in areas with a low potential for temporal bed elevation changes due to floods and a minimum of image distortion factors like riverbank shadows, surface sun reflection, and turbulence. An example of a river section is shown in Figure 3 for river Lågen.

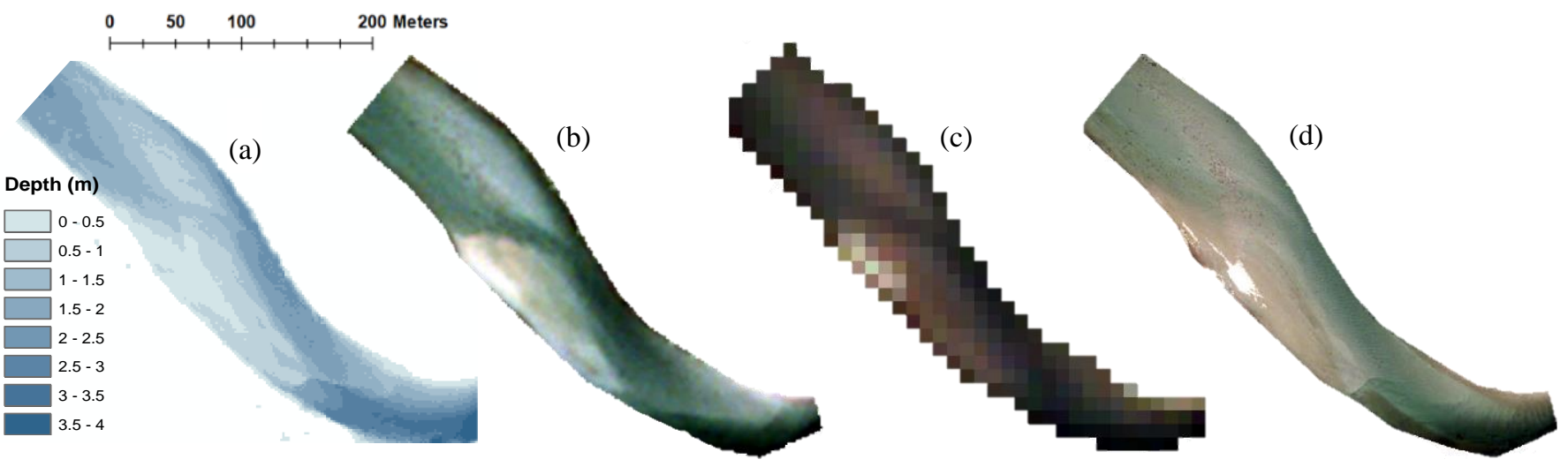

Figure 3. Example of training polygon depth and imagery for river Lågen. (a) Depth map, (b) Worldview-2 RGB ToA image (2 m resolution, (C) TPMO), (c) Sentinel-2 RGB ToA image (10 m resolution), (d) RGB aerial image (0.5 m resolution, (C) Kartverket and Geovekst).

In each polygon, we defined a longitudinal, mid-river centerline and added 17 equally spaced latitudinal lines along the centerline reaching from the left to the right riverbank. Each latitudinal line was transformed into cross-sectional points with fixed $2 \mathrm{~m}$ intervals. 
The cross-section point files were used as input for calculations of intercepts and slopes ([A], Figure 2).

\subsubsection{Coefficient Vector Calculations}

Four methods were used for calculating coefficient vectors from the image quantity $X$ to depth relationship in cross-sections: (1) a direct linear relationship $=b_{\text {dir }} ;$ (2) a direct linear relationship for cross-sections with $\mathrm{R}^{2}$ above $0.60=b_{\text {corr }}$; (3) basic regional average $=b_{\text {reg }}$; and (4) adjusted regional average $=b_{\text {reg_d } d b r}$. All four methods are described in the following section and summarized in Table 4.

Table 4. Summary of the four methods for depth retrieval using 17 cross-sections in each of the four rivers.

\begin{tabular}{clll}
\hline No. & Method & Coefficient Vector & Method Description \\
\hline 1 & Direct linear & $b_{\text {dir }}=\left[b_{0, d i r} b_{1, d i r}\right]$ & Direct linear fit with depth \\
\hline 2 & $\mathrm{R}^{2}$-corrected & $b_{\text {corr }}=\left[b_{0, \text { corr }} b_{1, \text { corr }}\right]$ & Direct linear with $\mathrm{R}^{2}>0.60$ \\
\hline 3 & Regional & $b_{\text {reg }}=\left[b_{0, \text { reg }} b_{1, \text { reg }}\right]$ & $\begin{array}{l}\text { Averaged across four rivers } \\
\text { using } b_{\text {corr }}\end{array}$ \\
\hline 4 & $\begin{array}{l}\text { Regional, depth and } \\
\text { brightness adjusted }\end{array}$ & $b_{\text {reg_dbr }}=\left[b_{0, \text { reg_dbr }} b_{1, \text { reg_dbr }}\right]$ & $\begin{array}{l}\text { Averaged across four rivers } \\
\text { using } b_{\text {corr }} \text { and corrected by } \\
\text { average estimated local depth } \\
\text { and normalized brightness }\end{array}$ \\
\hline
\end{tabular}

Using the cross-section point files in each river, we sampled RGB pixel values and observed depth in all images for each of the three platforms. Sampling was done using the nearest neighbor resampling technique. We calculated $X_{g}$ and $X_{b}$ for each sample point and assessed the direct linear relationship between $X_{g}$ and $X_{b}$, and observed depth in cross-sections. The quality of fit between calculated and observed depth was determined by calculating the coefficient of determination $\left(\mathrm{R}^{2}\right)$ for each cross-section. We repeated the process for all images across the three platforms in each of the four rivers. For each of the three platforms, we calculated a final river-specific coefficient vector $b_{d i r}=\left[b_{0, d i r} b_{1, d i r}\right]$ by averaging the individual cross-section vectors in all platform-specific images. From the initial cross-sectional $X_{g}$ and $X_{b}$ dataset, we removed cross-sections with a coefficient of determination less than 0.60 , based on an assumption of adequate linear fit above this threshold value. The river- and platform-specific $\mathrm{R}^{2}$-corrected coefficient vector $b_{\text {corr }}=\left[b_{0, \text { corr }} b_{1, \text { corr }}\right]$ was then calculated by averaging all remaining cross-section vectors in all platform-specific images. By averaging the four river-specific $\mathrm{R}^{2}$-corrected coefficient vectors $b_{\text {corr }}$, we obtained final multiple-river regional coefficient vectors $b_{\text {reg }}=\left[b_{0, \text { reg }} b_{1, \text { reg }}\right]$ for each platform.

We tested the relationship between the average depth and the coefficient vector in the cross-sections by setting up two separate linear regression models using coefficients $b_{0, d i r}$ and $b_{1, d i r}$ from the initial cross-sectional $X_{g}$ and $X_{b}$ dataset as predictor variables and depth, $d$, as the response variable. Linear regression was done separately for each platform, and the results were summarized as a platform-specific coefficient of determination averaged across all four rivers. Examples of linear models for the calculation of $b_{d i r}$ for Worldview-2 images in our study are given in Equations (4)-(7).

$$
\begin{gathered}
\text { For } X_{g} b_{0, d i r}=0.6526-1.4346 * \bar{d} \\
\quad b_{1, d i r}=-0.9313+5.0843 * \bar{d} \\
\text { For } X_{b} b_{0, d i r}=0.8061-2.0049 * \bar{d}
\end{gathered}
$$




$$
b_{1, \text { dir }}=-0.8532+3.8351 * \bar{d}
$$

In addition, we introduced a "brightness" variable $B R_{\text {local }}$ to adjust the regional coefficient vectors for the local variations in the red, green, and blue (RGB) pixel values $p_{r}$, $p_{g}$, and $p_{b}$. For each river, we calculated the normalized brightness value by dividing the median value of all three band image pixel values in each cross-section with the median RGB pixel value across all cross-sections within the study area.

$$
\begin{gathered}
B R_{\text {local }}=\text { median } R G B_{X S} / \text { median } R G B_{A l l} \\
\text { median } R G B=\text { median }\left[p_{r}, p_{g}, p_{b}\right]
\end{gathered}
$$

For each platform, in each of the four rivers, we calculated a local depth and brightness corrected regional coefficient vector $b_{\text {reg_d } d b r}=\left[b_{0, r e g \_} d b r b_{1, \text { reg_d } d b r}\right]$ by adding average estimated depth, $\bar{d}_{e s t}$, and the normalized "brightness" variable $B R_{\text {local }}$ as product variables to the regional coefficient vector $b_{\text {reg }}$ :

$$
\begin{aligned}
& b_{0, \text { reg_d } d b r}=b_{0, \text { reg }} * \bar{d}_{e s t} * B R_{\text {local }} \\
& b_{1, \text { reg_dbr }}=b_{1, \text { reg }} * \bar{d}_{\text {est }} * B R_{\text {local }}
\end{aligned}
$$

We used the statistical software R [41] and the package lme4 [42] for regression and statistics on depth average and brightness.

\subsubsection{Mean Error and RMSE Calculation}

To test the quality of depth retrieval from the coefficient vectors, we used mean error (ME) and root-mean-square error (RMSE) as accuracy and precision parameters, respectively. ME was calculated as the deviation between average calculated and observed depth. Thus, negative ME values represented an underestimation of depth, while positive values indicated an overestimation. RMSE was calculated as the square root of the mean of the squares of the deviations for $n$ predictions, as shown in Equation (12). All calculations of ME and RMSE were done using Microsoft Excel (2021).

$$
R M S E=\sqrt{\frac{\sum_{i=1}^{n}\left(\hat{d}_{i}-d\right)^{2}}{n}}
$$

\subsubsection{Polygon Validation of Linear Models}

For the assessment of model depth retrieval quality across platforms, we selected a separate validation location in each of the four rivers (Figure 4). A total of 100 randomly distributed points were generated within each validation polygon and used for bandspecific image pixel quantity and depth sampling (corresponding to step [G] in Figure 2). From the sampled image pixel quantities in the validation polygons, we applied the three bathymetry models from the initial training datasets:

1. A direct linear model using locally calculated coefficient vectors.

2. A basic regional model using coefficients averaged across the four rivers.

3. An adjusted regional model with basic regional model coefficients corrected by the local estimated average depth and image brightness. 

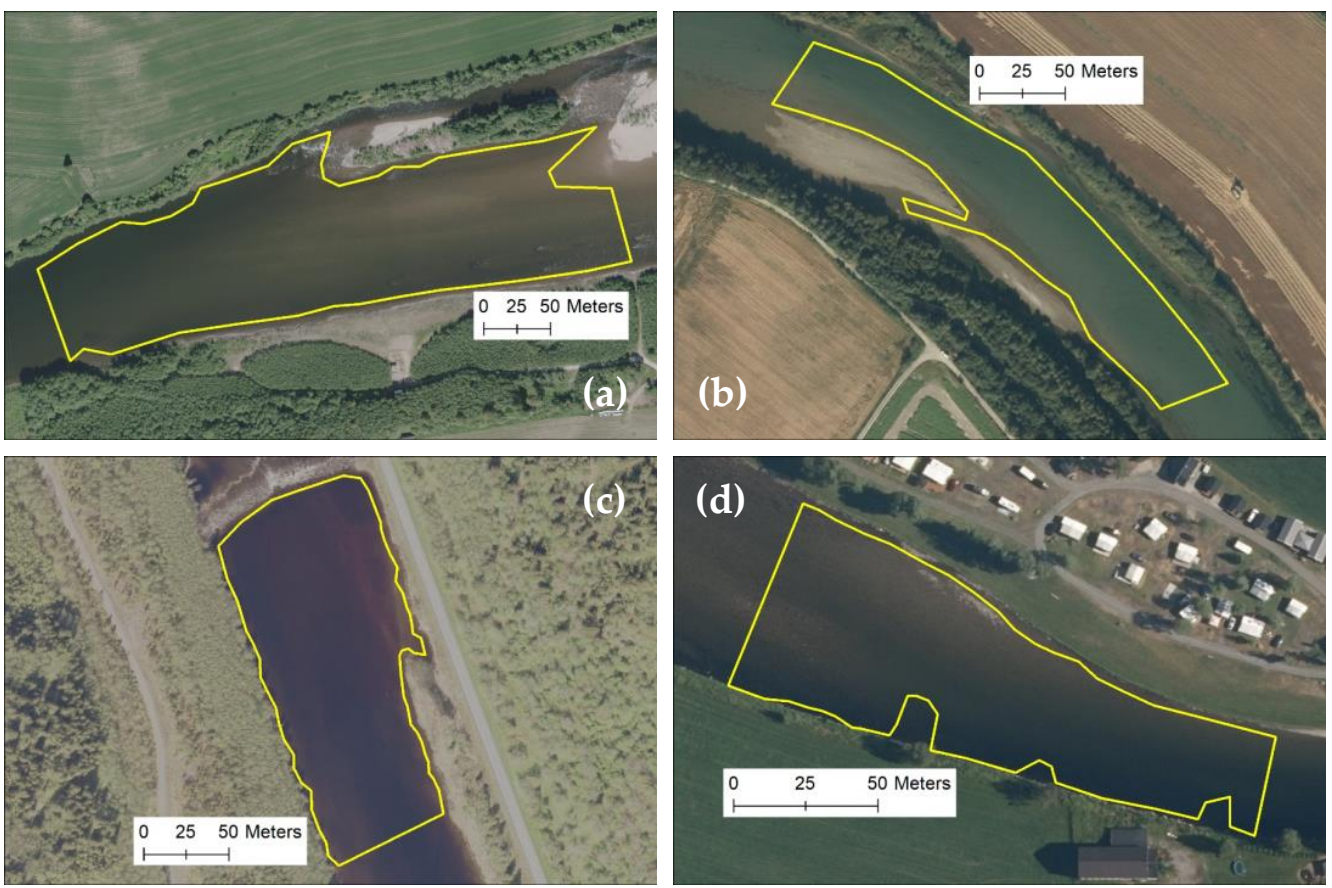

Figure 4. Validation polygons for the model quality assessment in rivers Gaula (a), Laagen (b), Nea (c), and Surna (d). Source: (C) Kartverket and Geovekst.

We used mean error, RMSE, and $\mathrm{R}^{2}$ as indicators of model quality. As the band combination blue on red provided the best overall model results on depth retrieval during the initial model calculations, we only applied this specific band combination in the final assessment. Initial calculations of depth from Sentinel-2 images in the validation polygons provided non-significant relationships to in-situ depths in all four rivers, and the platform was removed from the final assessment. Visual inspection of Sentinel-2 images in the validation polygons confirmed the low image quality and diffuse pixel quantities in the dry/wet zones along the riverbanks.

As the adjusted regional models used estimated local average depth and brightness as corrective factors, we needed to calculate these factors in the validation polygons. We split each validation polygon longitudinally into five sections. For each section, we used average in-situ depth in the 20 random points as a proxy for the estimated average depth. The section brightness was calculated by dividing the median section RGB value by the median RGB value in the whole validation polygon.

\section{Results}

\subsection{River-Specific Platform Coefficient Vectors in Cross-Sections}

Training data coefficient vectors $b_{d i r}$ and $b_{\text {corr }}$ for platforms Worldview-2, Sentinel-2, and aerial image are given in Table 5 . The overall best fit was obtained by using the blue on red band combination $X_{b}$ on the aerial images. Sentinel-2 images provided the least fitted models, especially for the green on red band combination $X_{g}$. Removing cross-sections with $R^{2}$ less than 0.60 and thus increasing the overall fit generally increased the absolute value of the coefficients. 
Table 5. Vector coefficients and $\mathrm{R}^{2}$ for (a) $b_{d i r}$ and (b) $b_{\text {corr }}$ for band combinations $X_{g}$ and $X_{b}$ for the three platforms in each of the four rivers. The total number of points in cross-sections $(n)$ is given in the last column.

\begin{tabular}{|c|c|c|c|c|c|c|c|c|c|}
\hline & & & & $X_{g}$ & & & $X_{b}$ & & \\
\hline River & Platform & $\mathrm{CV}^{1}$ & $\boldsymbol{b}_{0}$ & $\boldsymbol{b}_{1}$ & $\mathbf{R}^{2}$ & $\boldsymbol{b}_{0}$ & $b_{1}$ & $\mathbf{R}^{2}$ & $n$ \\
\hline \multirow[t]{6}{*}{ Gaula } & Worldview-2 & a & -0.89 & 5.67 & 0.71 & -1.38 & 3.72 & 0.70 & 611 \\
\hline & & $\mathrm{b}$ & -1.09 & 6.24 & 0.74 & -1.79 & 4.35 & 0.75 & 504 \\
\hline & Sentinel-2 & a & -0.05 & 3.61 & 0.42 & -0.18 & 1.93 & 0.37 & 638 \\
\hline & & $\mathrm{b}$ & -0.42 & 4.95 & 0.74 & -0.68 & 2.69 & 0.69 & 205 \\
\hline & Aerial image & a & 1.48 & 6.91 & 0.65 & 1.77 & 3.97 & 0.70 & 1395 \\
\hline & & $\mathrm{b}$ & 1.67 & 8.07 & 0.75 & 1.88 & 4.59 & 0.82 & 1026 \\
\hline \multirow[t]{6}{*}{ Lågen } & Worldview-2 & a & -1.25 & 5.44 & 0.57 & -1.88 & 4.13 & 0.58 & 1195 \\
\hline & & $\mathrm{b}$ & -1.61 & 6.67 & 0.80 & -2.34 & 4.93 & 0.78 & 565 \\
\hline & Sentinel-2 & a & -0.08 & 3.54 & 0.63 & -0.30 & 2.82 & 0.64 & 1780 \\
\hline & & b & -0.24 & 4.35 & 0.85 & -0.48 & 3.43 & 0.86 & 1051 \\
\hline & Aerial image & $\mathrm{a}$ & 0.42 & 5.46 & 0.89 & 1.19 & 4.67 & 0.85 & 597 \\
\hline & & $\mathrm{b}$ & 0.42 & 5.46 & 0.89 & 1.19 & 4.67 & 0.85 & 597 \\
\hline \multirow[t]{6}{*}{ Nea } & Worldview-2 & a & 0.04 & 1.28 & 0.31 & -0.19 & 0.96 & 0.31 & 1366 \\
\hline & & $\mathrm{b}$ & -0.29 & 2.21 & 0.67 & -0.63 & 1.75 & 0.67 & 320 \\
\hline & Sentinel-2 & $\mathrm{a}$ & -0.07 & 1.38 & 0.33 & -0.45 & 1.27 & 0.36 & 2030 \\
\hline & & $\mathrm{b}$ & -0.61 & 2.62 & 0.78 & -1.32 & 2.48 & 0.77 & 478 \\
\hline & Aerial image & $\mathrm{a}$ & 0.47 & 0.68 & 0.23 & 0.41 & 0.43 & 0.36 & 1317 \\
\hline & & $\mathrm{b}$ & 0.68 & 1.84 & 0.67 & 0.49 & 1.12 & 0.77 & 138 \\
\hline \multirow[t]{6}{*}{ Surna } & Worldview-2 & $\mathrm{a}$ & -0.45 & 2.76 & 0.64 & -0.56 & 1.82 & 0.64 & 432 \\
\hline & & $\mathrm{b}$ & -0.68 & 3.36 & 0.76 & -0.71 & 2.03 & 0.76 & 270 \\
\hline & Sentinel-2 & $\mathrm{a}$ & 0.15 & 1.57 & 0.47 & 0.65 & 0.04 & 0.56 & 595 \\
\hline & & $\mathrm{b}$ & -0.20 & 1.95 & 0.94 & 0.76 & -0.18 & 0.88 & 216 \\
\hline & Aerial image & $\mathrm{a}$ & 0.62 & 3.14 & 0.65 & 0.50 & 1.71 & 0.80 & 484 \\
\hline & & $\mathrm{b}$ & 0.65 & 3.65 & 0.76 & 0.49 & 1.77 & 0.83 & 313 \\
\hline
\end{tabular}

${ }^{1} \mathrm{CV}=$ Coefficient Vector.

Figure 5 shows examples of cross-section depth retrievals using coefficient vectors $b_{\text {dir }}$ and $b_{c o r r}$ for the $X_{b}$ band combination in rivers Lågen, Gaula, and Nea. For the Worldview2 image in river Lågen, both coefficient vectors led to an overestimation of depths in the shallow areas close to the left bank. The best fit was obtained by using the coefficient vector $b_{d i r}$. For the Lågen aerial image, both methods provided an adequate calculated versus observed depth fit.

For the Worldview-2 and the Sentinel-2 images in river Gaula, both coefficient vectors $b_{\text {dir }}$ and $b_{\text {corr }}$ underestimated the depths in the deeper part of the cross-section. For the aerial image in river Gaula, most methods provided an adequate fit to the observed depth. The presence of "noise" in the deeper parts of the aerial image can be observed as a slightly "fluctuating" riverbed in the depth calculations (Figure 5f).

River Nea was the shallowest river among the four in terms of average river section depth. For the Worldview-2 image, overall depth was overestimated along the crosssection. Both coefficient vectors provided a relatively good fit with the observed depth for the Sentinel- 2 image. For the aerial image in river Nea, both coefficient vectors were inadequate in estimating depth. 

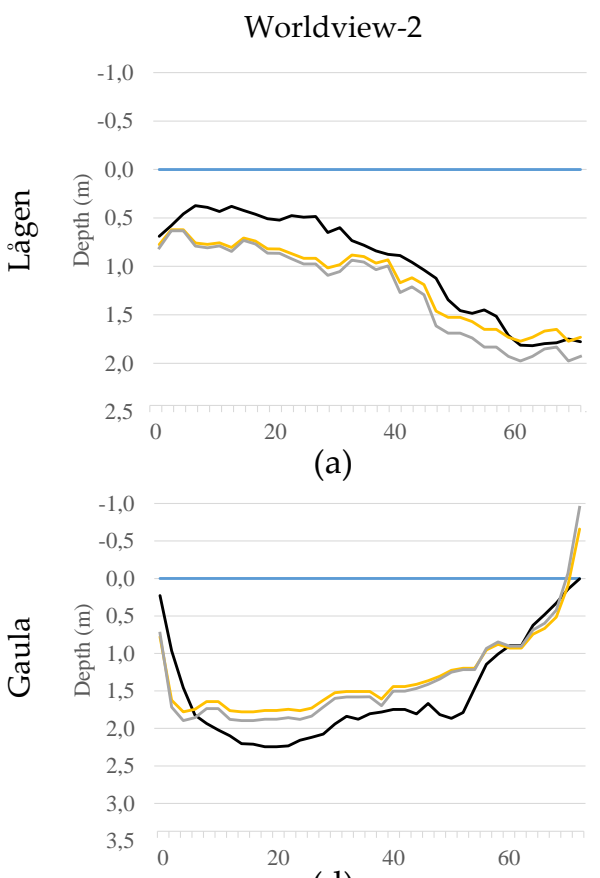

(d)



(g)
Sentinel-2

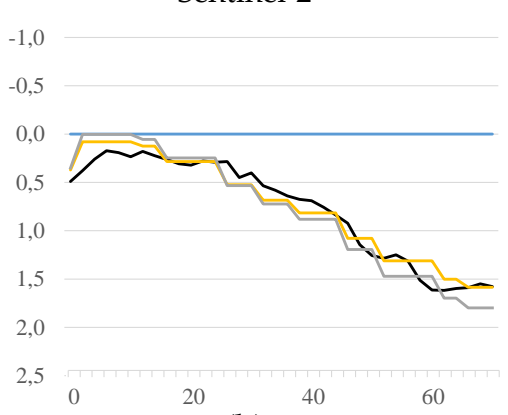

(b)

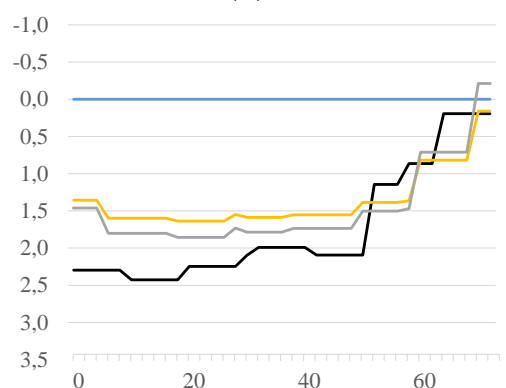

(e)

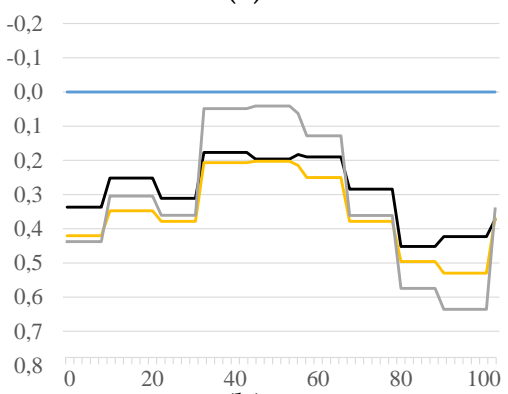

(h)
Aerial images

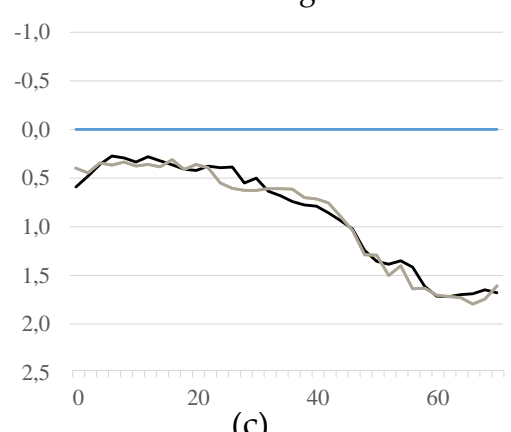

(c)

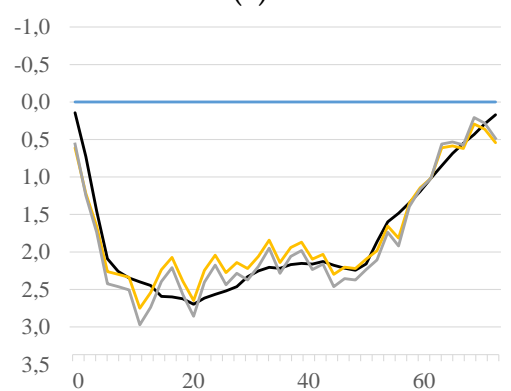

(f)

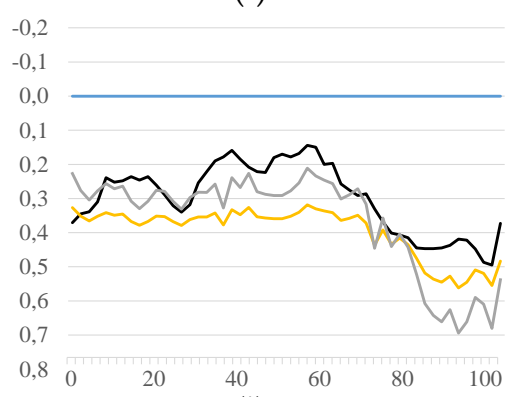

(i)

-Water surface - Bed elevation - Direct $-\mathrm{R}^{2}>0.6$

Figure 5. Examples of calculated versus observed depth in selected cross-sections. The horizontal axis is given in meters from the left bank. The columns represent platforms Worldview-2 (a,d,g), Sentinel-2 (b,e,h), and aerial images (c,f,i) for rivers Lågen $(\mathbf{a}-\mathbf{c})$, Gaula $(\mathbf{d}-\mathbf{f})$, and Nea $(\mathbf{g}-\mathbf{i})$. The lines represent the water surface, bed elevation, and depth calculated using the coefficient vectors $b_{d i r}$ and $b_{c o r r}$, respectively, for the $X_{b}$ band combination on the Y-axis.

\subsection{Cross-Section Mean Error and RMSE}

The cross-sectional average depth retrieval mean error was in the $-0.07-0.01 \mathrm{~m}$ range for all platforms and models. Excluding cross-sections with $\mathrm{R}^{2}<0.6$, reduced the mean error to $\approx 0$, while no overall reduction in RMSE was observed. RMSE across all platforms and models ranged from $0.15 \mathrm{~m}$ to $0.31 \mathrm{~m}$. While the cross-platform average mean error was slightly less for $X_{b}$, no overall difference in RMSE was observed between $X_{g}$ and $X_{b}$.

Average mean error and RMSE were lower in depths less than $2 \mathrm{~m}$ when compared to the inclusion of all depths (for coefficient vector $b_{d i r}$, Table 6). 
Table 6. Cross-sectional mean error and RMSE for depth retrieval on all depths (for $b_{\text {dir }}$ and $b_{\text {corr }}$ ) and depths below $2 \mathrm{~m}$ ( $b_{\text {dir }}$ only) across platforms and rivers for band combinations $X_{g}$ and $X_{b}$.

\begin{tabular}{|c|c|c|c|c|c|c|}
\hline \multirow[b]{2}{*}{ Platform } & \multirow[t]{2}{*}{$\mathrm{CV}^{1}$} & \multirow[t]{2}{*}{ Data Included } & \multicolumn{2}{|l|}{$X_{g}$} & \multicolumn{2}{|l|}{$X_{b}$} \\
\hline & & & ME & RMSE & ME & RMSE \\
\hline \multirow[t]{3}{*}{ Worldview-2 } & $b_{d i r}$ & All & $-0.06 \pm 0.09$ & 0.28 & $-0.07 \pm 0.11$ & 0.28 \\
\hline & & Depths $<2 \mathrm{~m}$ & $-0.01 \pm 0.08$ & 0.19 & $-0.02 \pm 0.08$ & 0.19 \\
\hline & $b_{\text {corr }}$ & $X S R^{2}>0.6$ & $0.00 \pm 0.17$ & 0.31 & $0.00 \pm 0.18$ & 0.31 \\
\hline \multirow[t]{3}{*}{ Sentinel-2 } & $b_{d i r}$ & All & $-0.04 \pm 0.06$ & 0.27 & $-0.04 \pm 0.06$ & 0.27 \\
\hline & & Depths $<2 \mathrm{~m}$ & $0.00 \pm 0.03$ & 0.18 & $0.00 \pm 0.04$ & 0.18 \\
\hline & $b_{\text {corr }}$ & $X S R^{2}>0.6$ & $0.00 \pm 0.08$ & 0.25 & $0.00 \pm 0.08$ & 0.28 \\
\hline \multirow[t]{3}{*}{ Aerial image } & $b_{\text {dir }}$ & All & $-0.04 \pm 0.05$ & 0.26 & $-0.03 \pm 0.05$ & 0.24 \\
\hline & & Depths $<2 \mathrm{~m}$ & $0.01 \pm 0.04$ & 0.16 & $0.00 \pm 0.03$ & 0.15 \\
\hline & $b_{\text {corr }}$ & $X S R^{2}>0.6$ & $0.01 \pm 0.07$ & 0.26 & $-0.01 \pm 0.05$ & 0.23 \\
\hline
\end{tabular}

${ }^{1} \mathrm{CV}=$ Coefficient Vector.

\subsection{Regionalization of Coefficient Vectors}

Using river-specific coefficient vector $b_{c o r r}$ (as given in Table 5) as input, we obtained platform-specific regional coefficient vectors $b_{\text {reg }}$ for the band combinations $X_{g}$ and $X_{b}$ (Table 7).

Table 7. The regional platform-specific coefficient vectors $b_{\text {reg }}$ for the band combinations $X_{g}$ and $X_{b}$ as an average of $b_{\text {corr }}$ in rivers Gaula, Lågen, Nea, and Surna.

\begin{tabular}{ccccc}
\hline & \multicolumn{2}{c}{$\boldsymbol{X}_{\boldsymbol{g}}$} & \multicolumn{2}{c}{$\boldsymbol{X}_{\boldsymbol{b}}$} \\
\hline Platform & $\boldsymbol{b}_{0, \text { reg }}$ & $\boldsymbol{b}_{1, \text { reg }}$ & $\boldsymbol{b}_{0, \text { reg }}$ & $\boldsymbol{b}_{1, \text { reg }}$ \\
\hline Worldview-2 & $-0.89 \pm 0.59$ & $4.39 \pm 2.10$ & $-1.31 \pm 0.85$ & $3.11 \pm 1.55$ \\
Sentinel-2 & $-0.37 \pm 0.22$ & $3.17 \pm 1.46$ & $-0.38 \pm 1.21$ & $1.99 \pm 2.17$ \\
Aerial image & $0.92 \pm 0.80$ & $4.65 \pm 2.67$ & $0.99 \pm 0.75$ & $2.81 \pm 1.74$ \\
\hline
\end{tabular}

We tested for an overall non-river-specific linear relationship between the coefficient vector $b_{d i r}$ and average depth in cross-sections for each of the three platforms. The results showed that the slope variable $b_{1, d i r}$ was significantly related to average depth in all platforms $(p<0.01$, Table 8$)$, while the intercept variable $b_{0, \text { dir }}$ was significantly related to depth in Worldview-2 images $\left(X_{g}\right.$ and $\left.X_{b}, p<0.01\right)$ and aerial images $\left(X_{b}, p<0.01\right)$. Sentinel-2 image intercept $\left(b_{0, \text { reg }}\right.$ for $X_{g}$ and $\left.X_{b}\right)$ were not significantly related to average depth.

Table 8. Quality of fit by coefficients of determination $\mathrm{R}^{2}$ for the band combinations $X_{g}$ and $X_{b}$ for the relationship between the direct linear coefficient vectors $b_{d i r}$ and average depth $\bar{d}$ in cross-sections.

\begin{tabular}{|c|c|c|c|c|c|c|c|c|}
\hline \multirow[b]{3}{*}{ Platform } & \multicolumn{4}{|c|}{$X_{g}$} & \multicolumn{4}{|c|}{$X_{b}$} \\
\hline & \multicolumn{2}{|c|}{$\boldsymbol{b}_{0, \text { dir }}$} & \multicolumn{2}{|c|}{$\boldsymbol{b}_{1, \mathrm{dir}}$} & \multicolumn{2}{|c|}{$\boldsymbol{b}_{0, \mathrm{dir}}$} & \multicolumn{2}{|c|}{$\boldsymbol{b}_{1, \mathrm{dir}}$} \\
\hline & $\mathbf{R}^{2}$ & $p$-Value & $\mathbf{R}^{2}$ & $p$-Value & $\mathrm{R}^{2}$ & $p$-Value & $\mathbf{R}^{2}$ & $p$-Value \\
\hline Worldview-2 & 0.93 & $<0.01$ & 0.93 & $<0.01$ & 0.95 & $<0.01$ & 0.98 & $<0.01$ \\
\hline Sentinel-2 & 0.00 & 0.93 & 0.94 & $<0.01$ & 0.07 & 0.48 & 0.74 & $<0.01$ \\
\hline Aerial image & 0.41 & 0.12 & 0.95 & $<0.01$ & 0.82 & $<0.01$ & 0.83 & $<0.01$ \\
\hline
\end{tabular}

We found that normalized brightness was significantly related to average depth in cross-sections in images with low levels of surface disturbance (Table 9). 
Table 9. The linear fit between the "brightness" factor $B R_{\text {local }}$ and average depth $\bar{d}$ in cross-sections for platforms Worldview-2, Sentinel-2, and aerial image.

\begin{tabular}{cccc}
\hline Platform & $\mathbf{R}^{\mathbf{2}}$ & $\boldsymbol{p}$-Value & $\begin{array}{c}\text { Number of Cross } \\
\text { Sections }\end{array}$ \\
\hline Worldview-2 & 0.61 & $<0.001$ & 34 \\
Sentinel-2 & 0.71 & $<0.001$ & 51 \\
Aerial image & 0.78 & $<0.001$ & 51 \\
\hline
\end{tabular}

Using the significant relationships between the coefficient vectors, average depth, and brightness, we calculated a depth- and brightness-adjusted $b_{\text {reg_d } d b r}$ for all images, as described in Equations (10) and (11). While no overall significant average depth-relation was found for intercept $b_{0, \text { reg }}$ for platforms Sentinel-2 $\left(X_{g}\right.$ and $\left.X_{b}\right)$ and aerial image (for $X_{g}$ ), we included the platforms in a final calculation of platform-specific $b_{r e g \_} d b r$ for comparison. An example of regional coefficient vector use in a cross-section is shown in Figure 6. The use of the adjusted coefficient vector $b_{\text {reg_d } d b r}$ improved the results of the basic regional coefficient vector $b_{\text {reg }}$ across platforms.

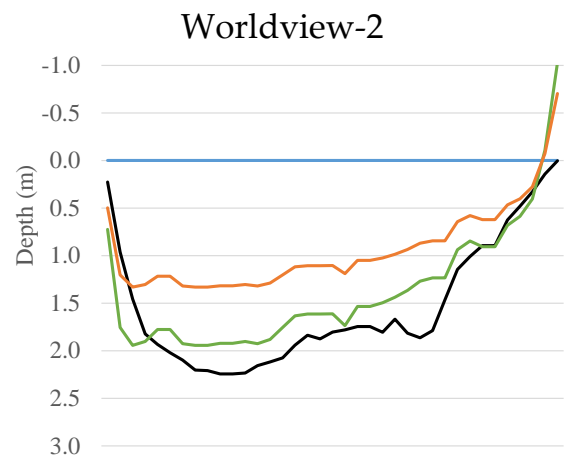

(a)

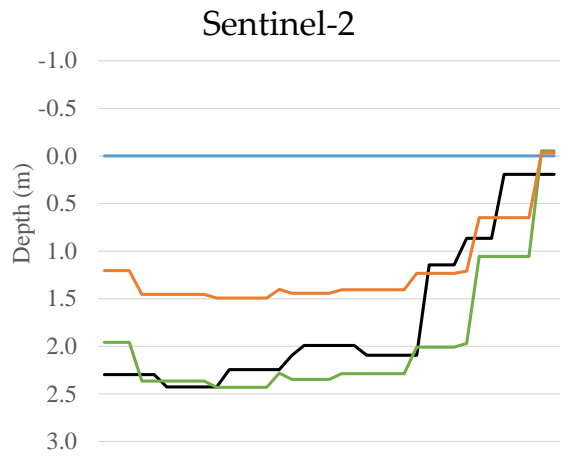

(b)

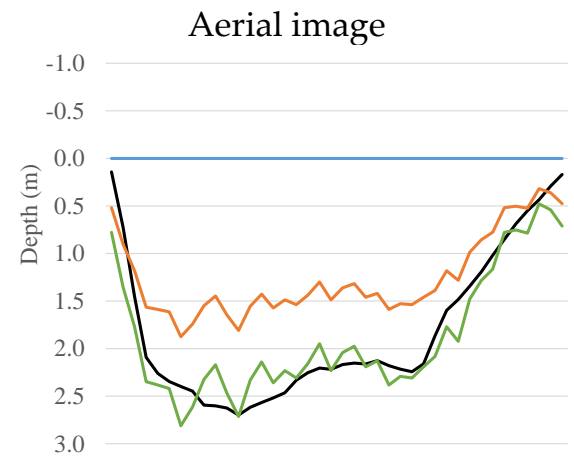

(c)

-Water surface —Bed elevation —Regional - Regional adjusted

Figure 6. Example of cross-section depth calculations in river Gaula using regional coefficient vectors $b_{\text {reg }}$ and $b_{\text {reg_d } d b r}$ for (a) Worldview-2, (b) Sentinel-2, and (c) aerial image. $b_{r e g}$ is the basic regional coefficient vector (orange line), while $b_{r e g \_} d b r$ is the regional coefficient vector with adjustment using estimated local average depth and a brightness factor (green line).

\subsection{Application and Quality Assessment of Regional Models in Validation Polygons}

In the final step of the study, we applied and assessed the regional models for the calculation of depth, using the band combination $X_{b}$ for platforms Worldview- 2 and aerial images in validation polygons. See Figure 7 for results on model depth in the validation polygon for river Gaula. Local river-specific models were also applied for comparison. The model performances of each of the three models were compared in terms of mean error, RMSE, and $\mathrm{R}^{2}$. 



Figure 7. Calculated depth in river Gaula using (a) local, (b) basic regional, and (c) adjusted regional models for band combination $X_{b}$ in a Worldview-2 image. The flow direction is from left to right. Negative depths are apparent in the downstream mid-section, where dry land is protruding from the water surface, and close to the left riverbank, where surface turbulence distorts the pixel quantities. Zonal differences in depth retrieval are observed in (c), where each zone has its specific estimated depth and brightness.

The overall performances of the basic regional models were equal to or higher than the local models for all rivers, with an exception for the aerial image in river Surna (Table 10). Performances of the adjusted regional models improved upon the local and basic regional models in rivers Gaula and Surna for the Worldview-2 image, and in river Gaula for the aerial image.

Table 10. Model performance results in validation polygons.

\begin{tabular}{|c|c|c|c|c|c|}
\hline Platform & River & Model & $\mathrm{ME}$ & RMSE & R2 \\
\hline \multirow[t]{12}{*}{ Worldview-2 } & \multirow[t]{3}{*}{ Gaula } & Local & -0.30 & 0.34 & 0.74 \\
\hline & & Basic regional & -0.30 & 0.34 & 0.76 \\
\hline & & $\begin{array}{l}\text { Adjusted } \\
\text { regional }\end{array}$ & -0.22 & 0.27 & 0.83 \\
\hline & \multirow[t]{3}{*}{ Lågen } & Local & 0.31 & 0.39 & 0.76 \\
\hline & & Basic regional & 0.07 & 0.27 & 0.76 \\
\hline & & $\begin{array}{l}\text { Adjusted } \\
\text { regional }\end{array}$ & 0.88 & 0.91 & 0.74 \\
\hline & \multirow[t]{3}{*}{ Nea } & Local & -0.58 & 0.66 & 0.52 \\
\hline & & Basic regional & 0.11 & 0.27 & 0.52 \\
\hline & & $\begin{array}{c}\text { Adjusted } \\
\text { regional }\end{array}$ & 0.36 & 0.43 & 0.47 \\
\hline & \multirow[t]{3}{*}{ Surna } & Local & -0.35 & 0.68 & 0.82 \\
\hline & & Basic regional & -0.32 & 0.54 & 0.82 \\
\hline & & $\begin{array}{l}\text { Adjusted } \\
\text { regional }\end{array}$ & -0.09 & 0.31 & 0.84 \\
\hline \multirow[t]{12}{*}{ Aerial image } & \multirow[t]{3}{*}{ Gaula } & Local & -0.39 & 0.43 & 0.77 \\
\hline & & Basic regional & -0.22 & 0.27 & 0.77 \\
\hline & & $\begin{array}{c}\text { Adjusted } \\
\text { regional }\end{array}$ & 0.22 & 0.27 & 0.78 \\
\hline & \multirow[t]{3}{*}{ Lågen } & Local & 0.17 & 0.22 & 0.91 \\
\hline & & Basic regional & -0.15 & 0.24 & 0.91 \\
\hline & & $\begin{array}{c}\text { Adjusted } \\
\text { regional }\end{array}$ & 0.46 & 0.48 & 0.91 \\
\hline & \multirow[t]{3}{*}{ Nea } & Local & -0.58 & 0.65 & 0.70 \\
\hline & & Basic regional & 0.52 & 0.60 & 0.70 \\
\hline & & $\begin{array}{c}\text { Adjusted } \\
\text { regional }\end{array}$ & 0.81 & 0.88 & 0.71 \\
\hline & \multirow[t]{3}{*}{ Surna } & Local & -0.54 & 0.68 & 0.83 \\
\hline & & Basic regional & 0.59 & 0.67 & 0.83 \\
\hline & & $\begin{array}{l}\text { Adjusted } \\
\text { regional }\end{array}$ & 1.00 & 1.22 & 0.84 \\
\hline
\end{tabular}

An example of the results of the model performance for depth retrieval is given in Figure 8 for the validation polygon in river Gaula. The best result using the Worldview-2 image was obtained by applying the adjusted regional model (Figure $8 \mathrm{~d}$, mean error $=-0.30$, RMSE $=0.34, R^{2}=0.83$ ). The best result for the aerial image was also obtained by using the adjusted regional model (Figure $8 \mathrm{~g}$, mean error $=0.22$, $\mathrm{RMSE}=0.27, \mathrm{R}^{2}=0.78$ ). 

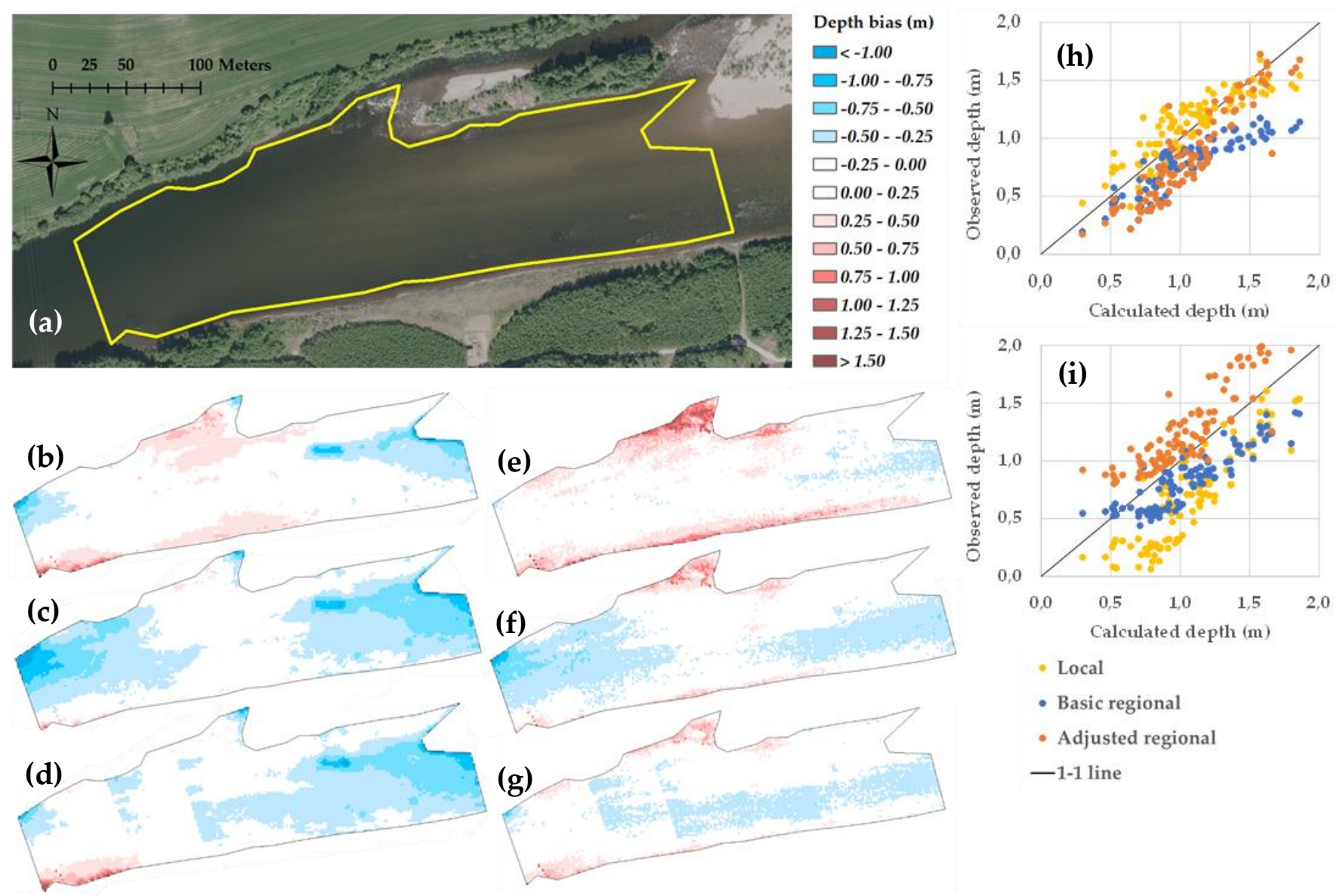

Figure 8. Model performance in river Gaula validation polygon (a). Depth bias maps using local models, basic regional models, and adjusted regional models, respectively, are given for the Worldview-2 image (b-d) and the aerial image (e-g). White indicates a mean error of less than $0.25 \mathrm{~m}$, while red and blue colors indicate an over- and underestimation of depth, respectively. Scatterplots for calculated versus observed depth using the three different models are given for the Worldview-2 image (h) and the aerial image (i).

For river Lågen, the local and basic regional models had matching model performances for both platforms, while the adjusted regional models led to higher levels of mean error and RMSE. For river Nea, while the basic regional model had the best relative model performance for the Worldview- 2 image (mean error $=0.11$, RMSE $=0.27, R^{2}=0.52$ ), the overall model performance was low for both image platforms and across models. For river Surna, the adjusted regional model performed best for the Worldview- 2 image (mean error $=-0.09$, RMSE $=0.31$, $R^{2}=0.84$ ), while for the aerial image, all three models had low performance levels.

\subsection{Application of an Adjusted Regional Model in River Nea}

In a separate study, using an adjusted regional model approach, as described above, we created bathymetry for a $30 \mathrm{~km}$ river reach in river Nea. River Nea was originally scanned using green LIDAR, but the resulting LIDAR data provided no data for river sections deeper than $0.5 \mathrm{~m}$. We applied the adjusted regional model setup on an aerial image to calculate depth in sections where LIDAR coverage was missing. From the calculated depths, we used information on local water surface elevation from the LIDAR dataset to transfer model depths to bathymetry. The bathymetry was used as input to a hydraulic model using Hec-RAS (HEC-RAS 5.0.7., https://www.hec.usace.army.mil/software/hec-ras, acessed on 17 August 2021). An example of bathymetry for a $5 \mathrm{~km}$ reach in river Nea is given in Figure 9. 




Figure 9. Bathymetry for a $5 \mathrm{~km}$ reach in river Nea. The bathymetry was calculated using an adjusted regional model setup on an aerial image combined with LIDAR data in dry areas. The green color outlines are the main river course which runs from right to left.

\section{Discussion}

A Web of Science publication search for the application of regional models for bathymetry (using keywords "regional", "remote sensing", "river", and "spectral analysis") resulted in no relevant publications. Thus, there is a lack of studies testing the potential for regional models applicable across several rivers. Our study outlines a novel method for calculating and applying regional models for depth retrieval using single predictors from multispectral images. In the first part of our study, we used a set of RS imagery and local bathymetry to set up linear regression models for depth retrieval in training data polygons for each of the four rivers. From these locally derived models, we extracted the intercept and slope coefficients to calculate regional coefficients. In the final part of the study, we applied the regional coefficients in regional linear models for application and performance assessment in a set of validation polygons. The regional models were calculated separately for Worldview-2, Sentinel-2, and aerial images.

We observed the best overall fit between depth $d$ and $X$ in high-resolution aerial images (0.10-0.50 m pixel width). The low-resolution Sentinel- 2 images (10 $\mathrm{m}$ pixel width) provided the least fitted models. Worldview-2 images (1.65-2.07 m pixel width) provided adequately fitted models in rivers Gaula and Surna, while less fitted models in rivers Lågen and Nea. As the average river width was in the range of 30-100 m, the pixel width would influence the capability to capture local variations in bed elevation, especially in the cross-sectional direction. Thus, the application of Sentinel-2 images with a pixel width of $10 \mathrm{~m}$ was least suitable for setting up models in our region.

Assessing the optimal band combination for depth retrieval, we found that the overall mean error and RMSE were lower for the $X_{b}$ pixel combination than for $X_{g}$ in Worldview-2 and Sentinel-2 images. For aerial images, $X_{g}$ provided fewer overall errors than $X_{b}$.

The overall depth retrieval was more successful in river sections with depths less than $2 \mathrm{~m}$. This issue is a known factor in image analysis [29]. As the image quality for all four rivers ranged from medium to low, we expected deeper parts to be less accurately calculated in the different models. We also tested the inclusion of the non-linear 2nd degree polynomial model in river Gaula. The polynomial model compensated for the limited range of $X$ by introducing a steeper slope vector in the deeper parts (Figure 10b). While a 
negative intercept $b_{0}$ in a linear approach could introduce negative calculated depths in shallow areas (Figure 10a), the polynomial model could potentially be applied to avoid negative depths in the calculations. As we tested the transferability of linear models with two coefficients, we did not include polynomial models in our study.

Direct linear relationship

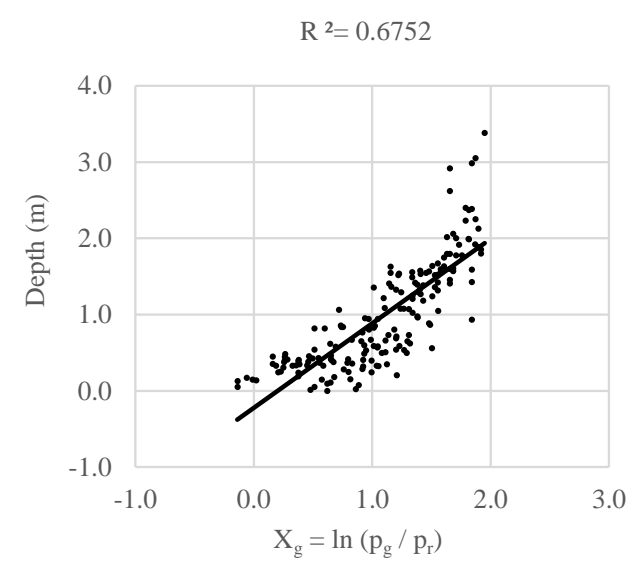

(a) 2nd degree polynomial relationship

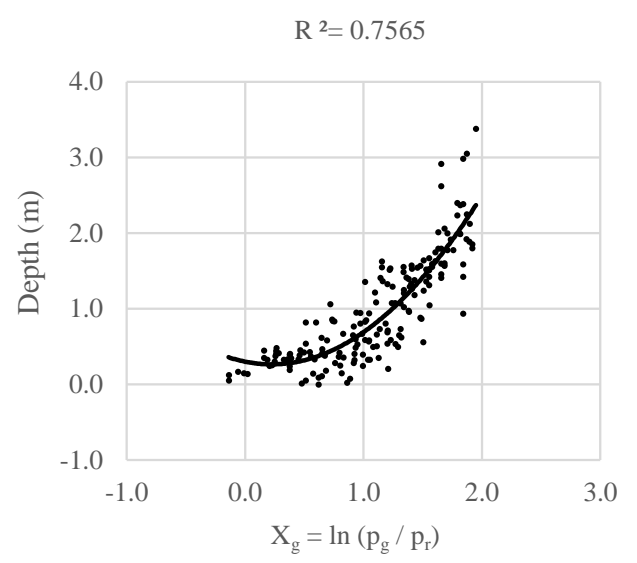

(b)

Figure 10. Examples of (a) direct linear and (b) 2nd degree polynomial relationships between depth and $X_{g}$ for a Worldview-2 image in river Gaula. The band combination $X_{g}$ is shown on the $x-$ axis, while the calculated depth $(\mathrm{m})$ is shown on the $y$-axis. The direct linear relationship would potentially lead to negative depths in the shallow areas $\left(X_{g}\right.$ below $\left.\sim 0.2\right)$, while the 2 nd degree polynomial relationship would avoid negative depths in the shallow areas.

\subsection{Local Adjustments of Regional Models}

We observed that local adjustments of basic regional models using estimated depth and "brightness" improved model performance for depth retrieval. Using the training data in the first part of the study, we found that average cross-sectional depth $\bar{d}$ was significantly related to $b_{d i r}$, more specifically for Worldview-2 and aerial images. From the training dataset, we also found a significant relationship between a normalized brightness factor $B R_{\text {local }}$ and average cross-sectional depth $\bar{d}$ for all platforms.

To assess the application of the two local correction factors in regional models, we used a $10 \times 10 \mathrm{~m}$ point grid in the training data polygons and sampled RGB values and in-situ depth. Assuming a $\bar{d}$ to $b_{d i r}$ relationship for Sentinel-2 images for comparison purposes, we calculated depth in each image by applying an adjusted regional vector coefficient for each point in the polygon point grid by using the setup from Equations (10) and (11). As a substitute for the estimated average local depth $\bar{d}_{\text {est }}$, we calculated the average depth of the 10 latitudinally closest points in the point grid. We used the same approach to calculate the local brightness factor $B R_{\text {local }}$ for each point. Results on the calculated depth range from the different coefficient vectors showed that using the locally adjusted regional coefficients provided the best overall fit with an observed depth range for all three platforms, although with larger uncertainties than for other coefficient vectors. While these results are optimistic in terms of depth retrieval, some limitations may apply to the use of adjusted regional coefficients. Firstly, as the regional coefficients are based on initial depth to image pixel value relations, the inclusion of estimated depth in a second iteration of the model may introduce interdependencies between variables. Secondly, as we used actual depths in 10 local points to set up the $\bar{d}_{e s t}$ for the polygon grid points, the models may be overfitted in terms of depth.

When applying adjusted regional models, care should be taken when partitioning the river into specific zones for local adjustment using estimated depth and brightness. As each zone will have its specific linear model, zonal boundaries may have abrupt, nonneglectable differences in depth. In the case of river Gaula, where the adjusted regional 
model was applied in five separate zones within the validation polygon, depth differences were observed as cross-sectional discontinuities (Figure 7c). Such discontinuities will be most apparent where neighboring zones have larger differences in estimated depth and brightness. To address and potentially avoid the issue of zonal boundary discontinuity, we suggest either to (1) define zone boundaries where there is a natural flow disruption, e.g., at weirs, riffle sections, or rapids, (2) smooth the resulting depth maps by crosssectional interpolation at zone boundaries, or (3) apply adjusted regional models in densely distributed cross-sections.

\subsection{The Problem of Time Lag between RS Imagery Acquisition and In-Situ Depth Measurements}

In an optimal assessment of the relationship between depth and $X$, the RS imagery and in-situ depth measurements would be captured and measured at approximately the same time. Any time lag between image capture and depth measurement could lead to errors in the results due to potential temporal hydromorphological changes in the bed elevation [23]. As several images in our assessment were captured at a different time than the in-situ depths, we sought to minimize potential time lag errors by selecting river sections with relatively stable bed conditions. We used visual inspection to select the training and validation locations in each of the four rivers. By visually comparing contrast-enhanced platform images and local bathymetry, we selected locations where the bed topography appeared constant over time. Figure 11 shows an example of visualization of bed elevation using images for rivers Gaula and Lågen. While the water surface levels differed, a similar bathymetry could be observed in both the Worldview-2 and aerial images. For river Nea, the river sections used for training data sampling and validation are both located between two low-head weirs in a bypass section with a minimum flow of $1.5 \mathrm{~m}^{3} \mathrm{~s}^{-1}$ during the summer season. The upstream dam and reservoir retain most floods creating a stable flow and bed elevation conditions throughout the year.
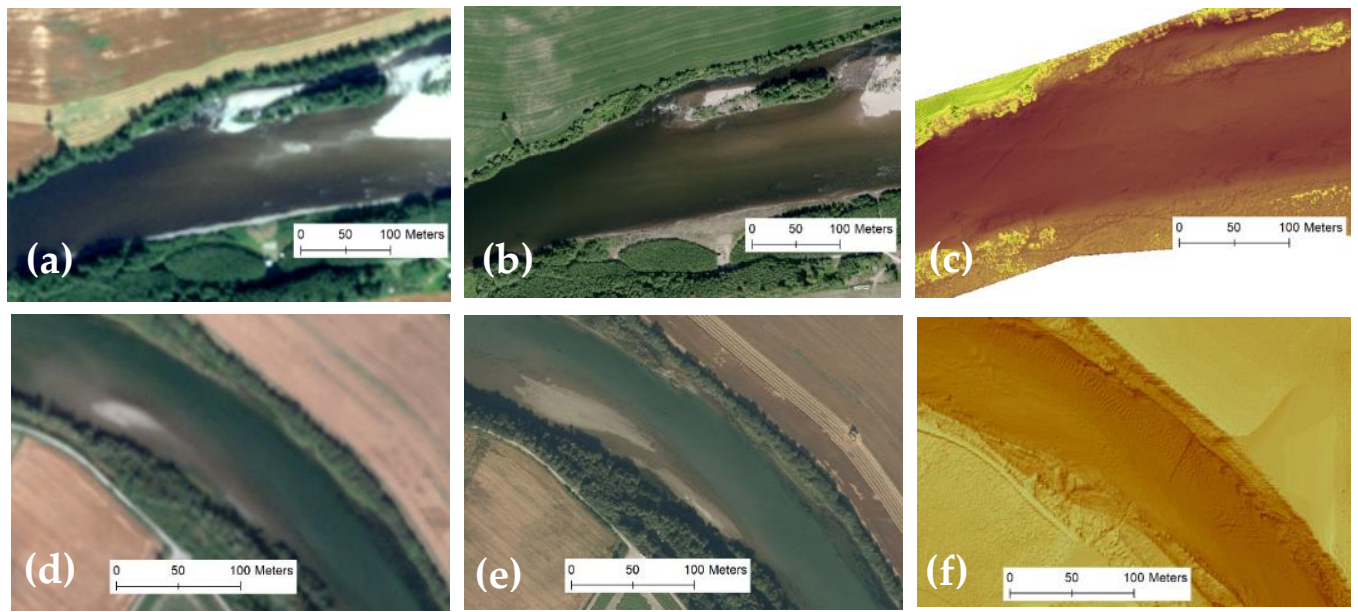

Figure 11. Visualization of bed elevation using Worldview-2 images (first column), aerial images (second column), and LIDAR bathymetry (third column) for rivers Gaula (a-c) and Lågen (d-f).

\subsection{Limitations and Considerations}

A range of limitations may apply when using remote sensing imagery for depth retrieval. Dependent on the image quality, most studies report the application to be optimal in shallow $(<2 \mathrm{~m})$ and clear rivers [43]. Others mention the capability of the platform sensor to adequately capture the surface nuances in radiance, which may determine the predictor range in the linear modeling of depth [40]. Additionally, local variation in substrate color and surface turbulence can induce large errors [44]. These factors and others must be carefully considered when applying spectral depth retrieval models.

Our methods were developed and calibrated in one single region of Norway. The local geology and hydromorphology may be specific to the region and using our methods 
outside of this region may require local adaptation through a recalibration of coefficient vectors. Another limitation in our study was the relatively low quality of many of our images. Clouds and sun reflections on the water surface were frequent, in addition to riverbank vegetation and mountain shadows. These factors reduced the number of river sections available for model training and validation.

As we developed our models to facilitate an overall regional mapping of depths, our models had limited accuracy and precision when compared to local bathymetry. For hydraulic or hydromorphological modeling with high levels of detail, our methods may be less suited and necessitate the application of locally calibrated models.

\subsection{Application in River Management}

Many rivers lack adequate data on the geomorphology and information on whole riverscapes from the connected floodplains and the riparian zone to riverbanks and riverbeds. While many countries have already established detailed surveys to provide digital terrain models for the terrestrial part, fewer surveys exist in the below-water part of the riverscape. In river management, regional assessments might include several rivers or water bodies, e.g., in relation to anthropogenic influences like flood protection and mitigation measures. Thus, it sometimes may be necessary to effectively establish a range of bathymetric data for different rivers within the same region.

The EU WFD requires the development and implementation of river management plans for all water bodies. When WFD targets are not met, the management plans must include mitigation measures such as habitat improvements, the creation of spawning grounds for fish, or other geomorphological changes. Norway has many rivers regulated by hydropower, where the terms of the license will be revised in the coming years [32]. These revisions of terms may lead to changes in environmental flow releases, adjustments of operation rules for reservoirs, and implementation of mitigation measures to improve ecological conditions in river reaches. Like the requirements for WFD, planning and implementation of mitigation measures often include the use of habitat-hydraulic models and detailed geomorphological information. Additionally, future operations of hydropower plants may include more hydropeaking due to changes in demand and renewable energy generation, and such scenarios might require extensive data and information on river bathymetry in relation to issues like sediment transport, erosion and deposition, ice buildup, and water temperature.

Challenges in river management are often related to obtaining good data and information about the current situation with appropriate spatial and temporal coverage. Our method may allow for a cost-effective retrieval of detailed riverbed information to improve modeling and assessments of the rivers for multiple purposes, including flood risk mapping, flood control operations, ecological mitigation measures for the implementation of the EU WFD, licensing, and revision of terms in hydropower rivers, urban, industrial, and infrastructure development as well as restoration of rivers.

\section{Conclusions}

By using multispectral images from three different platforms and publicly available green LIDAR data, we found significant relationships between image-derived quantities and depths. We found that platform-specific, regionalized models could potentially be used to create depth maps and subsequent bathymetry across rivers within a geographical region. By adding estimated local depth and a brightness factor to the regional models, the results on depth retrieval were improved. While the regional models were not tested outside of the four rivers included in this study, we believe our method for setting up regional models could potentially be promising for the application in other regions.

Author Contributions: Conceptualization, H.S. and K.A.; methodology, H.S. and K.A.; software, H.S.; validation, H.S. and K.A.; formal analysis, H.S.; investigation, H.S. and K.A.; resources, H.S., K.A. and A.H.; data curation, H.S.; writing-original draft preparation, H.S., K.A. and A.H.; writingreview and editing, H.S., K.A. and A.H.; visualization, H.S.; supervision, K.A. and A.H.; project 
administration, A.H.; funding acquisition, K.A. and A.H. All authors have read and agreed to the published version of the manuscript.

Funding: This research was funded by the Research Council of Norway, through HydroCen (Norwegian Research Center for Hydropower Technology, https: / www.ntnu.edu/hydrocen, accessed on 17 August 2021), project number 257588.

Data Availability Statement: All Sentinel-2 images used in the study are available at https:/ / scihub. copernicus.eu, acessed on 17 August 2021. Worldview-2 images are available upon application via educational institutions at https: / / earth.esa.int, acessed on 17 August 2021 and the study imagery was provided via project application and acceptance (project ID 57670). Aerial images were accessed at www.norgeibilder.no, acessed on 17 August 2021 via the institution, and restrictions may apply. Green LIDAR data for rivers Lågen and Gaula are publicly available at www.hoydedata.no, acessed on 17 August 2021 (restrictions may apply), while Green LIDAR data for river Surna were obtained from Statkraft AS and used with the permission of the owner (Statkraft AS). RiverSurveyor M9 data for river Nea are available on request from the corresponding author.

Acknowledgments: We thank Statkraft AS for supplying green LIDAR data for river Surna. We also thank Ingvild Brekke for her assistance in collecting and processing RiverSurveyor depth data for river Nea.

Conflicts of Interest: The authors declare no conflict of interest.

\section{References}

1. Grill, G.; Lehner, B.; Thieme, M.; Geenen, B.; Tickner, D.; Antonelli, F. Mapping the world's free-flowing rivers. Nature 2019, 569, 215-221. [CrossRef]

2. Ruff, J.F.; Keys, J.W.; Skinner, M.M. Clarks Fork Yellowstone River Remote Sensing Study. J. Hydraul. Div. 1974, 100, 719-729. [CrossRef]

3. Macconnell, W.; Niedzwiedz, W. Remote-Sensing the White River in Vermont. Photogramm. Eng. Remote Sens. 1979, 45, 1393-1399.

4. Belletti, B.; Rinaldi, M.; Buijse, A.D.; Gurnell, A.M.; Mosselman, E. A review of assessment methods for river hydromorphology. Environ. Earth Sci. 2015, 73, 2079-2100. [CrossRef]

5. Entwistle, N.; Heritage, G.; Milan, D. Recent remote sensing applications for hydro and morphodynamic monitoring and modelling. Earth Surf. Process. Landf. 2018, 43, 2283-2291. [CrossRef]

6. Mertes, L.A.K. Remote sensing of riverine landscapes. Freshw. Biol. 2002, 47, 799-816. [CrossRef]

7. Heritage, G.; Hetherington, D. Towards a protocol for laser scanning in fluvial geomorphology. Earth Surf. Process. Landf. 2007, 32, 66-74. [CrossRef]

8. Westoby, M.J.; Brasington, J.; Glasser, N.F.; Hambrey, M.J.; Reynolds, J.M. 'Structure-from-Motion' photogrammetry: A low-cost, effective tool for geoscience applications. Geomorphology 2012, 179, 300-314. [CrossRef]

9. Bizzi, S.; Demarchi, L.; Grabowski, R.C.; Weissteiner, C.J.; Van de Bund, W.J.A.S. The use of remote sensing to characterise hydromorphological properties of European rivers. Aquat. Sci. 2016, 78, 57-70. [CrossRef]

10. Carbonneau, P.E.; Bergeron, N.; Lane, S.N. Automated grain size measurements from airborne remote sensing for long profile measurements of fluvial grain sizes. Water Resour. Res. 2005, 41. [CrossRef]

11. Demarchi, L.; Bizzi, S.; Piégay, H. Regional hydromorphological characterization with continuous and automated remote sensing analysis based on VHR imagery and low-resolution LiDAR data. Earth Surf. Process. Landf. 2017, 42, 531-551. [CrossRef]

12. Hodge, R.; Brasington, J.; Richards, K. Analysing laser-scanned digital terrain models of gravel bed surfaces: Linking morphology to sediment transport processes and hydraulics. Sedimentology 2009, 56, 2024-2043. [CrossRef]

13. O'Sullivan, A.M.; Wegscheider, B.; Helminen, J.; Cormier, J.G.; Linnansaari, T.; Wilson, D.A. Catchment-scale, high-resolution, hydraulic models and habitat maps-A salmonid's perspective. J. Ecohydraulics 2021, 6, 53-68. [CrossRef]

14. Sundt, H.; Alfredsen, K.; Museth, J.; Forseth, T. Combining green LiDAR bathymetry, aerial images and telemetry data to derive mesoscale habitat characteristics for European grayling and brown trout in a Norwegian river. Hydrobiologia 2021. [CrossRef]

15. Carbonneau, P.; Fonstad, M.A.; Marcus, W.A.; Dugdale, S.J. Making riverscapes real. Geomorphology 2012, 137, 74-86. [CrossRef]

16. Kammel, L.E.; Pasternack, G.B.; Massa, D.A.; Bratovich, P.M. Near-census ecohydraulics bioverification of Oncorhynchus mykiss spawning microhabitat preferences. J. Ecohydraulics 2016, 1, 62-78. [CrossRef]

17. Grimaldi, S.; Li, Y.; Walker, J.P.; Pauwels, V.R.N. Effective Representation of River Geometry in Hydraulic Flood Forecast Models. Water Resour. Res. 2018, 54, 1031-1057. [CrossRef]

18. Petroselli, A. LIDAR Data and Hydrological Applications at the Basin Scale. Giscience Remote Sens. 2012, 49, 139-162. [CrossRef]

19. Mandlburger, G.; Hauer, C.; Wieser, M.; Pfeifer, N. Topo-Bathymetric LiDAR for Monitoring River Morphodynamics and Instream Habitats-A Case Study at the Pielach River. Remote Sens. 2015, 7, 6160-6195. [CrossRef]

20. Lejot, J.; Delacourt, C.; Piégay, H.; Fournier, T.; Trémélo, M.-L.; Allemand, P. Very high spatial resolution imagery for channel bathymetry and topography from an unmanned mapping controlled platform. Earth Surf. Process. Landf. 2007, 32, 1705-1725. [CrossRef] 
21. Kinzel, P.J.; Legleiter, C.J.; Nelson, J.M. Mapping River Bathymetry with a Small Footprint Green LiDAR: Applications and Challenges1. Jawra J. Am. Water Resour. Assoc. 2013, 49, 183-204. [CrossRef]

22. Westaway, R.M.; Lane, S.N.; Hicks, D.M. Remote survey of large-scale braided, gravel-bed rivers using digital photogrammetry and image analysis. Int. J. Remote Sens. 2003, 24, 795-815. [CrossRef]

23. Legleiter, C.J.; Roberts, D.A.; Marcus, W.A.; Fonstad, M.A. Passive optical remote sensing of river channel morphology and in-stream habitat: Physical basis and feasibility. Remote Sens. Environ. 2004, 93, 493-510. [CrossRef]

24. Gilvear, D.B.R. Analysis of remotely sensed data for fluvial geomorphology and river science. In Tools in Fluvial Geomorphology, 2nd ed.; Kondolf, G.M., Piégay, H., Eds.; John Wiley \& Sons, Ltd.: Hoboken, NJ, USA, 2016; pp. 103-132.

25. Bentley, S.G.; England, J.; Heritage, G.; Reid, H.; Mould, D.; Bithell, C. Long-reach Biotope Mapping: Deriving Low Flow Hydraulic Habitat from Aerial Imagery. River Res. Appl. 2016, 32, 1597-1608. [CrossRef]

26. Lyzenga, D.R. Passive Remote-Sensing Techniques for Mapping Water Depth and Bottom Features. Appl. Opt. 1978, 17, 379-383. [CrossRef]

27. Legleiter, C.J.; Roberts, D.A.; Lawrence, R.L. Spectrally based remote sensing of river bathymetry. Earth Surf. Process. Landf. 2009, 34, 1039-1059. [CrossRef]

28. Legleiter, C.J.; Harrison, L.R. Remote Sensing of River Bathymetry: Evaluating a Range of Sensors, Platforms, and Algorithms on the Upper Sacramento River, California, USA. Water Resour. Res. 2019, 55, 2142-2169. [CrossRef]

29. Niroumand-Jadidi, M.; Vitti, A.; Lyzenga, D.R. Multiple Optimal Depth Predictors Analysis (MODPA) for river bathymetry: Findings from spectroradiometry, simulations, and satellite imagery. Remote Sens. Environ. 2018, 218, 132-147. [CrossRef]

30. Niroumand-Jadidi, M.; Bovolo, F.; Bruzzone, L. SMART-SDB: Sample-specific multiple band ratio technique for satellite- derived bathymetry. Remote Sens. Environ. 2020, 251, 112091. [CrossRef]

31. Legleiter, C.J.; Roberts, D.A. A forward image model for passive optical remote sensing of river bathymetry. Remote Sens. Environ. 2009, 113, 1025-1045. [CrossRef]

32. Barton, D.N.; Bakken, T.H.; Madsen, A.L. Using a Bayesian belief network to diagnose significant adverse effect of the EU Water Framework Directive on hydropower production in Norway. J. Appl. Water Eng. Res. 2016, 4, 11-24. [CrossRef]

33. Juarez, A.; Alfredsen, K.; Stickler, M.; Adeva-Bustos, A.; Suarez, R.; Seguin-Garcia, S.; Hansen, B. A Conflict between Traditional Flood Measures and Maintaining River Ecosystems? A Case Study Based upon the River Lærdal, Norway. Water 2021, 13, 1884. [CrossRef]

34. The Norwegian Mapping Authority. Kartverket-Terms of Use. 2021. Available online: www.kartverket.no/en/api-and-data/ terms-of-use (accessed on 16 August 2021).

35. Statkraft. About Statk. UK. 2021. Available online: www.statkraft.co.uk/about-statkraft-uk (accessed on 16 August 2021).

36. Sontek. Riversurveyor ${ }^{\circledR}$ S5 M9. 2021. Available online: www.sontek.com/riversurveyor-s5-m9 (accessed on 16 August 2021).

37. Fan, X.W.; Liu, Y.B.; Wu, G.P.; Zhao, X.S. Compositing the Minimum NDVI for Daily Water Surface Mapping. Remote Sens. 2020, 12, 700. [CrossRef]

38. European Space Agency. Main Page. 2021. Available online: www.esa.int (accessed on 16 August 2021).

39. Copernicus Open Access Hub. Main Page. 2021. Available online: Scihub.copernicus.eu (accessed on 16 August 2021).

40. Shintani, C.; Fonstad, M.A. Comparing remote-sensing techniques collecting bathymetric data from a gravel-bed river. Int. J. Remote Sens. 2017, 38, 2883-2902. [CrossRef]

41. R Core Team. R: A Language and Environment for Statistical Computing; R Foundation for Statistical Computing: Vienna, Austria, 2021; Available online: http:/ / www.R-project.org/ (accessed on 16 August 2021).

42. Bates, D.; Maechler, M.; Bolker, B.; Walker, S. Fitting Linear Mixed-Effects Models Using lme4. J. Stat. Softw. 2015, 67, 1-48. [CrossRef]

43. Woodget, A.S.; Carbonneau, P.E.; Visser, F.; Maddock, I.P. Quantifying submerged fluvial topography using hyperspatial resolution UAS imagery and structure from motion photogrammetry. Earth Surf. Process. Landf. 2015, 40, 47-64. [CrossRef]

44. Kasvi, E.; Salmela, J.; Lotsari, E.; Kumpula, T.; Lane, S.N. Comparison of remote sensing based approaches for mapping bathymetry of shallow, clear water rivers. Geomorphology 2019, 333, 180-197. [CrossRef] 